MAHIR MUHAREMOVIĆ

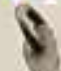
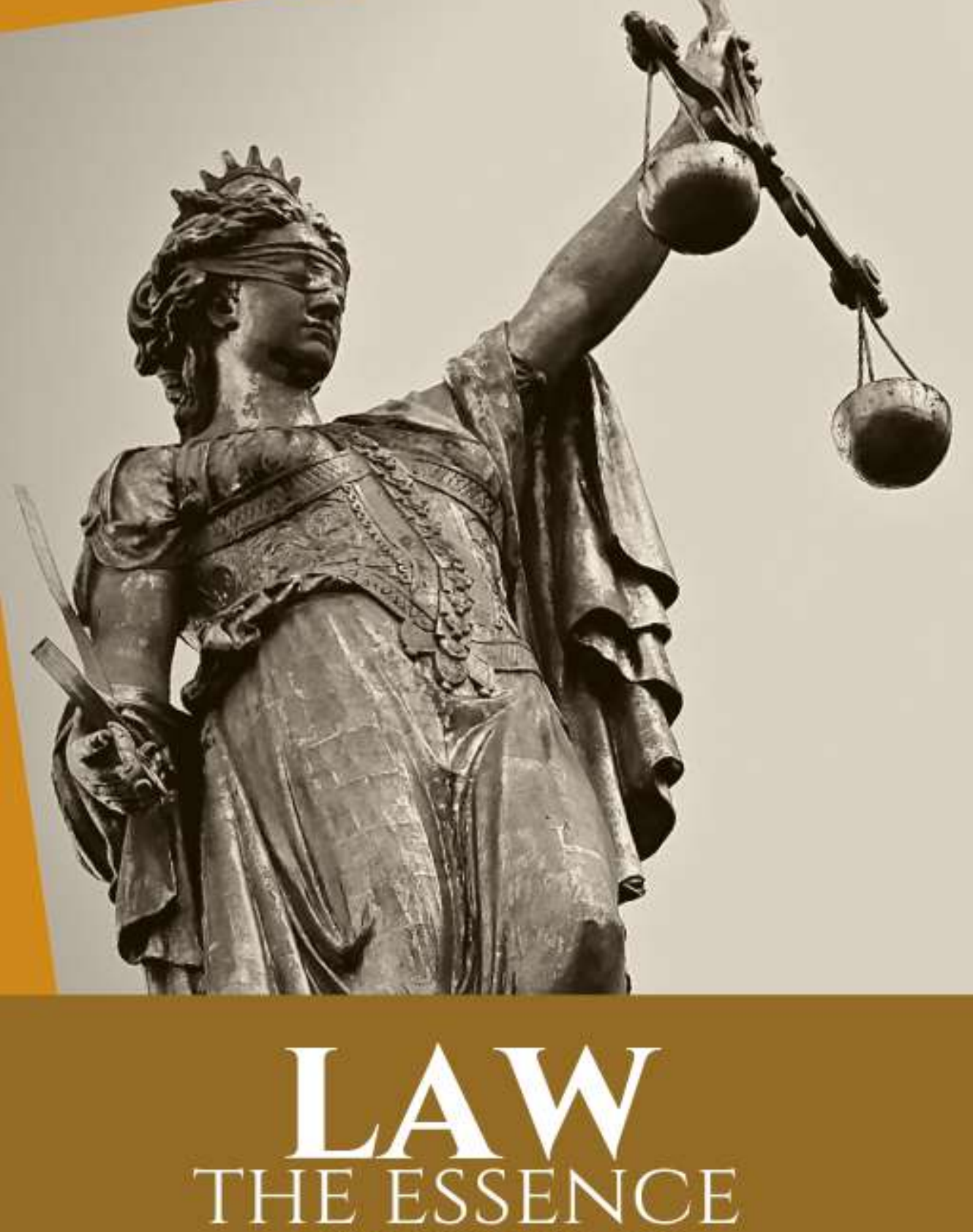

A DIFFERENT APPROACH 
In this brief book the author shows, using actual knowledge from socio-psychology, biology and cognitive science, thus freed of any preconceived ideology, the very essence of Law, regardless of time. space and culture it exists. Social norms are the fundamentals for Law development. Their role is to adjust behaviour of group members in their mutual interactions so that behaviour becomes regular and predictable. Law is the leading ideology of the modern State with the purpose to become the dominant normative order in society. In its essence. Law has never been more than an idea whose application, if at all, in real tife. primary depends of the potential of the State to "infect" its recipients with this idea. or at least the majority of its recipients. In simple terms, Law is little more than a form of psychology-it is a symbolic expression for the fact that the human mind responds in certain ways to various forms of social pressure Law as an idea, is not self-executing. It needs interpretation and application by its recipients (humans). In this process the recipients who have the final authority to decide what Law is are in reality the lawmakers.

Mahir Muharemović holds a LL.M. and Ph.D in Law and has worked as a Judge. He fusions his practical experience with scientific rigour in his works trying to give law a different touch.

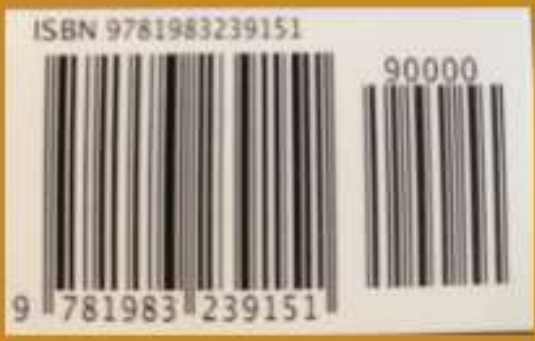




\section{Author \& Publisher:}

Dr. Mahir Muharemović

Right asserted to be identified as the author of this Work. All Rights Reserved.

\section{Editor \& Proofreading:}

Nejra M. Orić, LL.M.

ISBN 9781983239151

Cover picture :

Justitia- Goddess of Justice

Free for commercial use

No attribution required

https://pixabay.com/service/license/ 


\title{
LAW: THE ESSENCE
}

\author{
A Different Approach
}

Dr. MAHIR MUHAREMOVIĆ

2018 
M.Muharemović Law: The Essence

\section{CONTENTS}

INTRODUCTION 2

1.Norms as Social Reality 12

2.,,The Leviathan“ as the Source of Law 32

3. Law as an Ideology 41

4. Rethinking the Rule of Law 57

5. Law between States 72

6. An Order beyond Law? 80

$\begin{array}{ll}\text { SOURCES } & 87\end{array}$ 
M.Muharemović Law: The Essence

To my little family, my safe harbour.

\section{INTRODUCTION}

The goal of this paper is not to reproduce all this discussions or to take a well established position, but to make a contribution in an original way, freed of any preconceived ideology, explaining the very essence of Law, regardless of time, space and culture it exists, showing its anatomy ( structure) and physiology (function).

To reach the abovementioned goal I will favour an empirical approach. This approach entails that the only source of knowledge comes through our senses - e.g. sight, hearing etc. Thus, empiricism is the view that all knowledge is based on, or may come from experience ${ }^{1}$. The prime

${ }^{1}$ The signals from the different senses are treated by separated parts of the brain until, in a later stage of the process, the signals are integrated into an overall experience (Gaerdenfors, 2006, p.10). Elements of thinking according to Gaerdenfors (2006, p.25) are :

1 Sensations that are the immediate sensory impressions. The sensations often involve an (unconscious) evaluation of whether what is happening is good or bad. This is sometimes referred to as 'raw feels'.

2. Perceptions that are interpreted sensory impressions. Perceptions form one category of representations.

3. Imaginations (or images) that are not directly governed by sensory impressions, they are also called detached representations. Imaginations 
empirical method of inquiry in science is the experiment. The key features of the experiment are control over variables (independent, dependent and extraneous), careful objective measurement and establishing cause and effect relationships. But this method of gathering empirical data is difficult to use in the social sciences since social interactions entail humans with a (free) will and a variety of possible variables in these interactions. Experiments do not make much sense in studying social behaviour since the framework is too artificial (humans adapt their behaviour to stimuli in an artificial setting and the results vary with no possibility of a meaningful replication ). This is why the only way to gather empirical data in the social sciences is through observations. Through observations, if done properly, we can observe the actual behaviour of groups and individuals within groups in a natural environment. The negative side of this method is that the researcher cannot control the variables and compare the results with a parallel random control group which did not receive the treatment (you never now for sure what the cause and what the effect is in a given social relationship and it is very difficult to form afterwards a comparable randomly chosen control group with the same or similar properties)

Legal practitioners and scholars primary use the legaldogmatic method, which method is not sufficient to comprehend the totality of law, but it is the initial method

and perceptions are the elements from which the inner world is constructed. 
for studying law (Lukić, 1979, p.13). Law, in contrast to social rules expressed in moral, customs etc., represents a relatively coherent, logical and comprehensive structure, in short, a system of social rules. As a system it is a closed structure with its inner logic, where every element of this system (acts of parliaments, administrative acts, judicial decisions etc.) has its place and function, interacting so with other elements within the system, with a distinctive and clear hierarchy, striving to create a coherent and functional legal system. Having in mind the before said, the legaldogmatic method, in its essence, represents the logical analysis of legal norms within the legal system, to reveal their real content in order to adjust the behaviour of people according to these legal norms. The main purpose of this method is to discern us the real meaning of existing legal norms. In the search for the content and "true" meaning of a legal norm we have to analyse either acts of parliaments, administrative acts, judicial decisions, existing customs etc. and to do so it is necessary to interpret the signs which contain (symbolize) the intention of the creator (source) of a given norm. This "intention" is, mostly, transmitted via written texts, as one form for expressing language. And there lies the problem of this method. Language is imprecise, contradictive and full of ambiguities, which makes it very difficult, if even not impossible to discern the real will of the creator of a legal text. A reader of a text, in general, can only interpret the text according to his capacities (language proficiency, general or specific knowledge of the matter, educational background, social background etc.) and his/her idea of the purpose of a legal 
norm. Therefore, every legal act is in the sphere of "ought", and the application of a such act lies in the hands, or more precisely, in the head, of the person or group that is charged with its application, after rendering an interpretation of the text, creating so a finished legal norm. That means that the original will (intention) of the lawmaker does not always overlap with the final product after application. It is another question if one will of the lawmaker exists, at all, since making laws is a long lasting process with a chain of persons involved in this process (drafting, amending, negotiating etc.) and even when the final text of a law stands and is passed through a legislative body, it is doubtful if all legislators have the same interpretation of the text they voted for. Thus, this method does not satisfy the criteria of a scientific method ${ }^{2}$, because it can not explain or

2 Scientific method refers to a standardized set of techniques for building scientific knowledge, such as how to make valid observations, how to interpret results, and how to generalize those results. The scientific method must satisfy four characteristics :

-replicability: Others should be able to independently replicate or repeat a scientific study and obtain similar, if not identical, results.

-precision: Theoretical concepts must be defined with such precision that others can use those definitions to measure those concepts and test that theory.

-falsifiability : A theory must be stated in a way that it can be disproven. Theories that cannot be tested of falsified are not scientific.

-parsimony: When there are multiple explanations of a phenomenon, scientist must always accept the simplest or logically most economical explanation. (Bhattacherjee, 2012, p. 5) 
predict what the actual legal norm is. Legal rules are normative in character as they dictate how individuals ought to behave (Kelsen, 1967). They make no attempt either to explain, predict, or even to understand human behaviour. Their sole function is to prescribe it. In short, doctrinal research is not therefore research about law at all. The normative character of the law also means that the validity of doctrinal research must inevitably rest upon developing a consensus within the scholastic community, rather than on an appeal to any external reality (Chynoweth 2008). In the end, it is more a stage in the data gathering process within text analysis.

On the other side, the sociological method does not bother with the inner (logical) content of a legal norm, instead it focuses on the social causes of legal norms, because law is a social construct (Lukić, 1979, p.14). This method enables us to reveal the cause, intention and the impact of a certain legal norm on the given society. But, not every sociological approach to law does stand for a scientific approach to law, because most of the sociological "explanations" of law are "theoretical models of human action that make such grand simplifying assumptions that they have little predictive or explanatory value when applied to the real world." (McIntyre, 2006, p. 3) Here it should be stressed out that we arrive at scientific laws and theories through a process of logic (theory) and evidence (observations). In science, theories and observations are interrelated and cannot exist without each other. Theories provide meaning and 
significance to what we observe, and observations help validate or refine existing theory or construct new theory. Any other means of knowledge acquisition, such as faith or authority cannot be considered science (Bhattacherjee, 2012, p. 3). That means, concrete, legal science can only be science if its theories can be tested against evidence based on empirical data ${ }^{3}$. The real power of scientific testability is negative, not positive. Testing allows us not merely to confirm our theories but to weed out those that do not fit the evidence (McIntyre, 2006, p. 22).

But what is the subject of study when the written laws and other legal acts are not the primary source of knowledge about law? It is the actual behaviour of the subjects (humans) that apply the laws and how to improve, based on such observations, the regulation of social affairs. This answer seems simple, but it bears a very difficult task as it poses questions about the applicability of the scientific method on human behaviour. Human social relations,

\footnotetext{
${ }^{3}$ All scientific researchers systematically collect and analyse empirical data (raw, unorganized facts that can be observed about a phenomenon, event or behaviour of interest by human senses, and that need to be processed ) Empirical data can be in the form of impressions, words, sentences, photos, symbols, numbers and so forth. Depending on the kind of data (numerical-quantitative or qualitative) to be collected and processed, we can apply quantitative or qualitative scientific methods. The data collection methods typically associated with qualitative research methodology include document analysis, interviews (individual or through focus groups), and participant observation. The data collection methods typically associated with quantitative research methodology include distributing questionnaires and measuring interventions by conducting a randomized controlled trial.
} 
which are far more complex than the subject matter of any of the natural sciences. The number of variables at work in influencing any individual's behaviour is so large that it is very difficult to study them scientifically. Human beings' behaviour is not perfectly rational, in the sense of consistent logical ordering of the way in which they solve problems (Drobak, ed., 2006, p. 51). Furthermore, it is almost impossible to be objective about our own behaviour and as human beings, we are free to act in any way that we choose at any time that we choose. Once we become aware of any purported regularity in our behaviour that may be discovered by social science, we are free to change it. But in social science, as in natural science, this does not mean that we should not try to do the best job that we can.

In this sense, research in the social sciences, including law, has to be based on observed behaviour and a critical analysis of the observed to draw patterns which all together forms experience ${ }^{4}$. that enables to act (every other goal

\footnotetext{
${ }^{4}$ Human experiences have been the most efficient data-processing algorithms in the universe, until now. Other animals probably have experiences that we humans can barely imagine. Bats, for example, experience the world through echolocation. Just as in the human world every object has a characteristic shape and colour, so in the bat world every object has its echo-pattern." (Harari, 2016) That is why Hayek wrote in The Sensory Order (1952):
}

"perception is thus always an interpretation, the placing of something into one or several classes of objects. The qualities which we attribute to the experienced object are, strictly speaking, not properties of that object at all, but a set of relations by which our nervous system classifies them. Or, to put it differently, all we know about the world is of the nature of theories, and all experience can do is change these theories." 
does not make any sense in social science, even in the natural sciences), but always having in mind that such experience is limited and time only can show how deep this limitation maybe is. This is why research is the constant reminder, through the process of finding new and testing previous data, in the pursuit to falsify previous knowledge, that our actual knowledge is limited or false.

But what counts as empirical data in law, at all? This is, for example, extracted information of behaviour and experience, generated by applying law, which can be found

In this regard, modern cognitive science asserts that "the world presented to us by our perceptions is nothing like reality. Our perceptions will be tuned to fitness, but not to truth. Evolution has shaped us with perceptions that allow us to survive. They guide adaptive behaviours. But part of that involves hiding from us the stuff we don't need to know. Objects, like the particles of physics, have no objective, observer-independent features, according to quantum physics. The object I see is a description created by my sensory system to inform me of the fitness consequences of my actions. Evolution shapes acceptable solutions, not optimal ones. Objects are mental representations." (Hoffman, 2016).

Thus, our minds do not reproduce reality; rather they attempt to interpret the very complex relationships in what are always theories. We may know all the facts and numbers possible about a particular set of events, but to order them and to explain them requires theory, and that theory, obviously, is a construction of the mind. This does not mean that all results are subjective. Obviously, what we try to do is to test the theories we have against the evidence so that we can arrive at rough, very rough, estimates of the reliability of such theories. There is an intimate connection between the mind and the external environment. 
in texts of court/administrative decisions ${ }^{5}$, other documents and in their executions in reality (qualitative data) or we take information about cases and court systems (among other things) and translate the information into numbers (quantitative data) that we analyse using statistical tools ${ }^{6}$ (Epstein \& Martin, 2014).

In the end, Law is made by humans for humans ${ }^{7}$, and that is the reason why biological and psychological basic patterns have influence on law- because of that law can be explained anthropologically, e.g. the strive for freedom or security. It is possible anthropologically to explain why and how humans create law or how they react on legal rules (Rodi, 2014 , p.8). That means that law can also be studied by an interdisciplinary approach and that is why I am in this paper

${ }^{5}$ Heidegger argued that texts are the means by which readers can not only read about an author's experience, but also relive the author's experiences ( in : Bhattacherjee, 2012, p. 117).

${ }^{6}$ Statistics is applied mathematics, and mathematics is a subset of logic. Abbott (2013) says about mathematics that" we have to anthropocentrically display the data in the one way that looks appealing to our senses. Mathematics is a merely mental abstraction that serves useful purposes. All physical laws and mathematical expressions of those laws are a compression or compact representation. They are necessarily compressed due to the limitations of the human mind. Therefore, they are compressed in a manner suited to the human intellect. The real world is inherently noisy and has a stochastic component, so physical models are idealizations with the rough edges removed."

${ }^{7}$ Homo sapiens - the species sapiens (wise) of the genus Homo (man). I will use the term 'Human' to denote members of the species Homo sapiens. 
M.Muharemović Law: The Essence

using a variety of literature (secondary sources) ranging from social psychology, behavioural science, cognitive science and biology, or in short, knowledge based on empirical evidence. 
M.Muharemović Law: The Essence

\section{Norms as Social Reality}

"Human beings are rule-following animals by nature; they are born to conform to the social norms they see around them, and they entrench those rules with often transcendent meaning and value." (Fukuyama, 2011)

In the empiricist view, a social norm is conduct favoured consistently enough throughout a society to be expressed as a code of principles. It reaches its precise form in each culture according to historical circumstance. Strong innate feeling and historical experience cause certain actions to be preferred; we have experienced them, and have weighed their consequences, and agree to conform with codes that express them. The empiricist view concedes that moral codes are devised to conform to some drives of human nature and to suppress others. The empiricist view recognizes that the strength of commitment can wane as a result of new knowledge and experience, with the result that certain rules may be desacralized, old laws rescinded, and formerly prohibited behaviour set free (Wilson,1998).

There is no law of deterministic causality in social relations, as it is the case in natural occurrences. If someone does not follow a given social norm, he/she can face certain sanctions, prescribed and executed by the society (social exclusion, seizure of property, physical harm, death etc.) 
On the other hand, social norms can only prescribe a behaviour that is possible to execute in reality, given the constraints of the physical world in which humans act and the factual situation in a given society. Otherwise, such norms would be senseless and useless since no one would be able to comply with them (Lukić, 1979, p.20). But social norms can impact reality, as long as they stay in the framework of the possible, since humans following such norms can change their environment.

\section{Social Groups and Social Norms}

As it can be noticed from the previous said, social norms are always the result of social (group) interaction. Here it should be stated, that there was never a period in human evolution when human beings existed as isolated individuals; the primate precursors of the human species had already developed extensive social, and indeed political, skills; and the human brain is hardwired with faculties that facilitate many forms of social cooperation. The state of nature might be characterized as a state of war, since violence was endemic, but the violence was not perpetrated by individuals so much as by tightly bonded social groups. Human beings do not enter into society and political life as a result of conscious, rational decision. Communal organization comes to them naturally, though the specific ways they cooperate are shaped by environment, ideas, and culture. Indeed, the most basic forms of cooperation predate the emergence of human beings by millions of years. Biologists have identified two natural sources of cooperative behaviour: kin selection and 
reciprocal altruism. In biological evolution it is not the survival of a given organism that matters but the survival of that organism's genes. This produces a regularity that was formulated as the principle of inclusive fitness or kin selection, which holds that individuals of any sexually reproducing species will behave altruistically toward kin in proportion to the number of genes they share. The desire to pass resources on to kin is one of the most enduring constants in human politics. The ability to cooperate with genetic strangers is referred to by biologists as reciprocal altruism, and in addition to kin selection is the second major biological source of social behaviour found in many species of animals. Social cooperation depends on the individuals' potential to be able to work together. A form of morality could evolve spontaneously as rational decision makers interact with one another over time, even though motivated in the first instance by nothing more than self-interest. (Fukuyama, 2011, pp.30-31)

Group $^{8}$ members tend to conform to group norms (i.e. think and act in accordance with group norms), either because

${ }^{8}$ A group exists when two or more individuals define themselves as members of a group, emphasizing common identity: sharing the view with others that you belong to the same group. Forming groups enables humans (and other social animals) to deal more effectively with enemies or predators, and allows cooperation in areas such as raising children, farming or hunting.(sociobiological perspective). Groups help us to understand our world. Argues that people want to hold accurate views of the world. They can do this by validating their beliefs either against 'physical reality. People turn to others especially for beliefs for which there is no physical reality. These theories propose that seeing oneself and others as members of groups helps to reduce uncertainty and make sense of our world. Being a member of a group often provides guidelines for the way we should behave and think (cognitive 
perspective). A utilitarian perspective argues that people derive benefits from groups. It argues that social relations (including those within groups) help to fulfil the individual's needs and often take the form of exchange processes. These exchanges might involve material goods (e.g. borrowing a tool, selling your car) or interpersonal helping (e.g. helping a friend move house), but also psychological 'goods' such as love, friendship or approval. Enduring exchange relations between two or more people are more effectively organized when people form a (more or less stable) group. Thus, groups exist because they facilitate mutually beneficial social exchange. People may leave groups (if possible) when they are unhappy about the benefits relative to the costs of group membership, or when alternative groups exist that have a better cost-benefit ratio. These three perspectives are complementary rather than mutually exclusive.

There exist four types of groups: intimacy groups (e.g. family); task groups (e.g.jury member); social categories (e.g.Americans); and loose associations (e.g.people at the bus stop). Intimacy groups mainly fulfil people's need to belong, task groups help fulfil people's need for achievement, and social categories help people fulfil identity-related needs. In the end, it is acknowledged that a classic five-stage model of group development exists: forming, storming, norming, performing and adjourning. In the first stage, when the group is forming, group members feel insecure because they do not know each other and do not know what is expected of them. As a consequence, interactions are usually polite and inhibited. In this first stage, people get to know each other and develop a shared identity as members of the same group. Once people have got to know each other, they enter the second stage (storming). The challenge in the second stage is to develop a group structure. Here issues of leadership and influence are at stake, and as group members may compete about different roles in the group, there may be conflicts and disagreements. Most groups will overcome this, and when a group structure and group roles have been established, they can move on to the third stage, norming. In this stage, group members develop close ties, and come to agree upon the group's goals and develop norms that govern group interaction. Once this has been achieved, the group enters the performing stage. Because group structure and group norms have been established, the group's efforts 
group norms are internalized - that is, become part of the individual's belief and value system - or because group norms are enforced by the (anticipated) reaction of other group members to normative and anti-normative behaviour. If everybody adheres to group norms, other group members' behaviour becomes more predictable and therefore can be anticipated. Group norms are also an important source of information about social reality. Often, people rely on what many people see as valid and true as an accurate reflection of (social) reality. Another important function of norms is that conformity to group norms illustrates one's group commitment - it shows that one is 'a good group member'. Group norms should therefore be seen on the one hand as enforcing their own maintenance, and on the other as subject to change over time and situations. Group norms are thus both an influence on group process and an outcome of group process. (Hewstone, Stroebe \& Jonas, ed., 2012) Therefore, it can be stated that "social life is like chess in that many individual actions are connected to a set of common conceptions of rules. The primary rules of chess are directives which are accepted by each player as socially binding: he knows that he can only move his pawns according to the rules, and he knows that if he does not abide by this rule he will be met by a protest by his opponent". (Ross in : Wacks, 2012, p.155)

can be directed towards achieving the group's task. Although it is probably still necessary to engage in behaviours to maintain a positive atmosphere in the group, most activities will be task-related. The final stage of group development is adjourning. When the task has been accomplished or is abandoned, the group will end. (see more in : Hewstone, Stroebe \& Jonas, ed., 2012) 
Why Social Norms are followed?

But, the question of the cause for norm-abiding behaviour of humans is more complex. According to Fukuyama (2011), rule following for human beings is not primarily a rational process but one that is grounded in the emotions. The human brain has developed certain emotional responses that amount to autopilot mechanisms promoting social behaviour. These emotional responses make human beings conformist, norm following animals. While the specific content of norms is culturally determined ("respect your ancestors"; "don't light up a cigarette at a dinner party"), the faculties for norm following are genetically based, just as languages vary across cultures while being rooted in a universal human faculty for language. All human beings, for example, feel the emotion of embarrassment when they are seen violating a norm or rule followed by their peers. Embarrassment is clearly not a learned behaviour. Norm following is embedded in human nature via the specific emotions of anger, shame, guilt, and pride. We feel anger when a norm is violated. We feel shame when we ourselves fail to live up to the norm, and we feel pride when we have the approbation of the community for achieving a collectively valued goal. Human beings also invest emotion in metanorms, norms about how to properly formulate and enforce norms. They want to see that "justice is done," even when they have no direct selfinterest in the outcome of a particular case. The grounding of normative behaviour in the emotions promotes social cooperation and has dearly conferred survival benefits as the human species evolved into its present form. 
Economists argue that blindly following rules can be economically rational, since calculating optimal outcomes in every situation is often costly and counterproductive. If we had to constantly negotiate new rules with our fellow human beings at every turn, we would be paralyzed and unable to achieve routine collective action. The fact that we become attached to certain rules not as means to short-term goals but as ends in themselves greatly enhances the stability of social life (Fukuyama, 2011, pp.39-40). That is the main reason why religion is one of the most successful normative orders in human history. It is a source of social cohesion that permits human beings to cooperate far more widely and securely than they would if they were the simple rational and self-interested agents. Collective action begins to break down as the size of the cooperating group increases. In large groups, it becomes harder and harder to monitor the individual contributions of members; free riding and other forms of opportunistic behaviour become much more common. Religion solves this collective action problem by presenting rewards and punishments that greatly reinforce the gains from cooperation in the here and now (Fukuyama, 2011, p.38).

The unique forms of cooperation practiced by modern humans became possible when early humans acquired the intellectual and linguistic abilities necessary to create them and uphold them. In biological usage, communication is nearly synonymous with attempted manipulation. It is a low-cost way of getting someone else to behave in a way favourable to oneself. Coupled with intelligence, symbolic language would have enabled early humans to translate their affective reactions to the behaviour of members of their groups into words and communicate such reactions to 
those who performed the behaviours and to third parties. Not only would it have enabled them to express their immediate approval and disapproval with words such as "good" and "bad," but it would also have enabled them to pass judgment on events that occurred in the past and to make judgments about events that could occur in the future. It would have enabled them to transform primitive threats and promises into long-term social contracts and commitments. Language and intelligence endow humans with the capacity to resolve their conflicts of interest through negotiation and discussion. The process of strategic interaction and the adaptive value of resolving conflicts of interest through moral argumentation have implications for the evolution of rules of conduct and universal norms of justice. (Krebs, 2008)

\section{Biological and Psychological Foundations of Norms}

From a biological standpoint, norms have arisen by evolution through the interplay of biology and culture ${ }^{9}$. If human propensities to cooperate or defect are heritable: some people are innately more cooperative, others less so. To the heritability of moral aptitude add the abundant

\footnotetext{
${ }^{9}$ Culture a social system that is characterized by the shared meanings that are attributed to people and events by its member (Hewstone, Stroebe \& Jonas, ed., 2012). Here I should remark that, as a general rule, "Biology enables, Culture forbids." This is because Culture tends to argue that it forbids only that which is unnatural. But from a biological perspective, nothing is unnatural. Whatever is possible is by definition also natural. A truly unnatural behaviour, one that goes against the laws of nature, simply cannot exist, so it would need no prohibition. ( see in : Harari 2014)
} 
evidence of history that cooperative individuals generally survive longer and leave more offspring. Following that reasoning, in the course of evolutionary history genes predisposing people toward cooperative behaviour would have come to predominate in the human population as a whole. Such a process repeated through thousands of generations inevitably gave rise to moral sentiments. Every person vividly experiences these instincts variously as conscience, self-respect, remorse, empathy, shame, humility, and moral outrage. They bias cultural evolution toward the conventions that express the universal moral codes of honour, patriotism, altruism, justice, compassion, mercy, and redemption. The dark side of the inborn propensity to moral behaviour is xenophobia. ${ }^{10}$ Because personal familiarity and common interest are vital in social transactions, moral sentiments evolved to be selective. People give trust to strangers with effort, and true compassion is a commodity in chronically short supply. Tribes cooperate only through carefully defined treaties and other conventions. They are quick to imagine themselves the victims of conspiracies by competing groups, and they are prone to dehumanize and murder their rivals during periods of severe conflict. They cement their own group

\footnotetext{
${ }^{10}$ Part of what defines a group is the distinction between who is 'in' and who is 'out'. Groups exist by virtue of their members, but also by the fact that there are some people who are not members of the group and may indeed be members of other groups. Accordingly, people's perceptions of their membership groups are affected by the comparison between their own group and other groups, and group members' perceptions of their group are also contingent on what differentiates their group from other groups (Hewstone, Stroebe \& Jonas, ed., 2012).
} 
loyalties by means of sacred symbols and ceremonies. Their mythologies are filled with epic victories over menacing enemies. (Wilson, 1998) Does this mean that our behaviour is deterministic? Not necessarily. Rather, there is a trinity of forces - genes, environment, and stochasticism ${ }^{11}$ - that governs all of biology including behaviour, with the stochastic component referring to the inherent uncertainty of the physical properties of matter (Cashmore, 2010, p 4500 ). In general, all behaviour is the product of interactions among three factors: (1) the organism's genetic endowment, which is a product of its evolution; (2) its experience; and (3) its perception of the current situation. (Pinel \& Barnes, 2018, p.49) It is widely accepted, that "good environmental conditions enable the developing of the genetic maximum, bad environmental conditions hinder the genetic potential to manifest." (Meyer, 2015, p.264) But, human beings have a degree of free will. That freedom is not radical, however, and it is curtailed by a number of internal and external events and constraints (Edelman in: Cashmore, 2010. p.4500). ${ }^{12}$

11 random, randomly determined- happening without method or
conscious decision 12 A more radical picture of the human free will is presented by Cashmore (2010, pp.4501-4502), who iterates that studies indicate that consciousness is something that follows, and does not precede, unconscious neural activity in the brain. He further states, that "we may not consciously control our own actions, but the cognitive mechanisms that create the illusion that we do keep society functioning. Whereas the impressions are that we are making "free" conscious decisions, the reality is that consciousness is simply a state of awareness that reflects the input signals, and these are an unavoidable consequence of genes, environment, and stochasticism. I believe that free will is clearly an 
M.Muharemović Law: The Essence

Development and Evolution of Norms

One of the most interesting questions posed by the idea of social norms is the question of why particular norms emerge in particular societies. A related question is why some sorts of norms are more likely than others to prove "sticky" (i.e., more likely to be internalized and followed even when external incentives are missing). In some cultures men wear ties; in others, togas or kilts. But there is an important subcategory of norms that are far more universal and that are seen in most societies. Examples include the norm of abiding by the law even when authorities are absent; the norm of keeping one's commitments to others; and, more generally, the norm of treating others as you would like them to treat you. It should be obvious what these "deeper" norms have in common. They are all significantly otherregarding. Other-regarding rules of conduct are especially likely to be socially "codified" into norms, and especially likely to prove sticky, because human beings are predisposed to other-regarding behaviour. Efficient norms are more likely to survive, and that as a result norms tend to evolve in the long run to favour efficient behaviours. Norms tend to support efficient behaviours because people have an innate preference for utilitarian (welfare-improving) norms. When the social conditions are right - when a respected authority tells us we ought to look out for others, when we believe those others are also other-regarding - we in fact

illusion. it must give rise to an evolutionary selective advantage. Consciousness confers the illusion of responsibility." 
behave like intuitive utilitarians, and take account of others' welfare as well as our own. (Drobak, ed., 2006, p.30) Cooperation that seems "irrational" from the perspective of an individual organism can still evolve if it benefits the individual's family, or potential exchange partners, or, in some cases, fellow members of the individual's tribe or group. For similar reasons, other-regarding behaviour may play an evolutionary role not only in the evolution of social organisms, but in the evolution of social institutions that promote cooperation within a group in a fashion that allows that group to thrive at the expense of other groups whose institutions do not encourage cooperative behaviour (Drobak, ed., 2006, pp.26-27) . One reason why humans may obey other-regarding norms is because they internalize them, at least when social and economic conditions are favourable. Contemporary norms scholars frequently emphasize the role that bystanders play in enforcing norms by punishing norm-breakers with social sanctions such as dirty looks, disparaging remarks, ostracism, and the like. ${ }^{13}$ People who obey other-regarding norms may perceive individuals who violate these norms as selfish recalcitrants whose non-cooperation threatens the welfare of others whom the norm enforcer cares about. This perceived threat triggers other-regarding spite that makes a bystander

\footnotetext{
${ }^{13}$ Humans may be the only species that is disposed to punish free riders and those who behave unfairly toward third parties. There is a great deal of evidence that people are inclined to react more strongly to being treated unfairly by others than to treating others unfairly, to hold others to higher standard of fairness than they hold themselves, and to reckon costs and benefits for themselves and others in different ways.(Krebs, 2008, pp.234-235)
} 
willing to incur the personal cost associated with punishing a norms-breaker through dirty looks, disparaging remarks, and confrontations. By increasing the cost of selfish behaviour, social sanctions decrease the relative cost of obeying norms of altruism. When the cost of altruistic behaviour declines, the supply increases. Other-regarding norms are more likely to be adopted and followed when people believe they enjoy the support of a respected authority. (Drobak, ed., 2006, p.32) Thus social norms may work best at promoting other-regarding behaviour when obeying (or enforcing) the norm is not too burdensome. When compliance with other-regarding norms becomes too costly, compliance falters (Drobak, ed., 2006, p.33).

The idea of other-regarding norms it tightly connected to the question what is the right "measure" to say that some norms are fair and just, and other are unfair and unjust. Or to be more specific: why it is justified that some group members enjoy more privileges (e.g. more food) than others? This has something to do with the inherent sense of justice that humans, but also other animals, possess. A sense of justice consists of thoughts and feelings about what is fair and unfair and what people deserve from and owe others (rights and duties). To make fair decisions, people must use fair and impartial procedures such as the Golden Rule, balanced discussion, or democratic decision making (Krebs, 2008, p.229). A sense of justice stems from a system of mechanisms. Sometimes people derive conceptions of justice from one mechanism, sometimes from another. Sometimes more than one mechanism is activated, and when this occurs, the activated mechanisms may work in concert to support the same decision, or they may engender internal conflict (Krebs, 2008, p.230). The 
first phase in the evolution of a sense of justice involved the evolution of cooperative behavioural dispositions and the affective reactions that support them. For cooperative dispositions to evolve, individuals must inherit genes that guide the creation of mechanisms that dispose them to behave in cooperative ways, and these mechanisms must pay off better genetically than competing mechanisms such as those that dispose them to behave in selfish ways. If other members of one's group behave cooperatively, each individual can come out ahead by doing less than his or her share and taking more. If those who are disposed to behave selfishly contribute more replicas of their genes to future generations than those who are disposed to behave fairly, selfish dispositions will be selected and evolve. Ironically, however, as the number of selfish members of a group increases, there are fewer and fewer cooperative individuals to exploit, jeopardizing the system of cooperation and forcing selfish individuals to interact with one another, to their mutual detriment. Others will interact with those who behave selfishly and by increasing the probability that selfish individuals will be punished-either by their interaction partners or by other members of their group. Accounting for the evolution of dispositions to punish third parties is tricky, because if we assume that it is costly to inflict punishments, those who refused to accept responsibility for administering punishments would fare better than those who accepted responsibility.(Krebs, 2008, pp.231-232) Members of groups make rules to formalize their agreements about how they should be treated by others, and they invoke sanctions to induce others to uphold the rules. The rules that members of groups invent to control the behaviour of others end up controlling their behaviour. Inasmuch as recipients are more receptive to some moral 
prescriptions than to others, recipients serve as agents of selection, determining which prescriptions succeed, get repeated, and develop into rules and moral norms. There is evidence that judgments and rules that uphold fair, balanced, and reversible solutions to social conflicts - such as those prescribed by the norm of reciprocity and the Golden Rule-constitute universal moral norms. Not all moral rules and norms are fair or rational. Following Aristotle, Darwin (1874) distinguished between two types of rules, akin to culturally universal and culturally relative moral norms. "The higher [moral rules] are founded on the social instincts, and relate to the welfare of others. They are supported by the approbation of our fellowman and by reason. The lower rules . . . arise from public opinion, matured by experience and cultivation ... [and may lead to] the strangest customs and superstitions, in complete opposition to the true welfare and happiness of mankind."(Krebs, 2008, pp.236-237) Most people locate their sense of justice in a mental mechanism they call their conscience. Humans differ from other animals, however, in their ability to construct portable cognitive representations of others and store them in their minds, to view events from others' perspectives, and to imagine how others will respond to their behaviour. After people internalize mental images of others, they may experience these images as approving and disapproving of the things they do in private, and this may be experienced as a "voice of conscience." (Krebs, 2008, pp.238-239) 
Who creates Social Norms?

It is undisputed that social norms exist to regulate behaviour of individuals within a framework of a group. But, who says, in a given group, what proper behaviour is, at all? Or more technically, which authority ${ }^{14}$ creates social norms? First of all, it is clear, at least from a scientific standpoint, that the "source" of social norms can only be a human being or a group of human beings, since to comply with social norms you have to live in groups and to possess certain cognitive abilities to receive, understand and behave in accordance with a certain social rule that is communicated to you by other members of a group. That's the reason why it is impossible to impose social rules to animals, since their cognitive abilities are restricted compared to humans, and even when you impose a certain behaviour to an animal (by training) it will not understand the meaning and purpose of it. That does not mean that animal groups do not have their own norms. On the contrary, from every group interaction stems a certain set of rules in order to make life in groups possible. But this norms, compared to human social norms, are not so complex. Coming back to the question of the norm-giving authority in a human group, we have to go back to our far ancestor- the chimp, to understand the process of authority creating. The chimp and human behaviours are almost completely parallel:'" The primary difference is that human beings are more deadly because they are able to use a wider and more lethal suite of

\footnotetext{
${ }^{14}$ Authority- the ability to settle conflicts and set rules based on their status within the hierarchy.
} 
weapons. The politics of dominance within those hierarchies, however, is reminiscent of politics within human groups. While physical size and strength matter, dominance is ultimately achieved through an ability to cooperate with others ${ }^{15}$. Chimpanzees seem to understand

15 The most commonly believed theory argues that accidental genetic mutations changed the inner wiring of the brains of Sapiens, enabling them to think in unprecedented ways and to communicate using an altogether new type of language (Harari.2014). It is interesting, according to some other theories, that the human brain grew as rapidly as it did for the reason to be able to cooperate and compete with other human beings. Human beings in effect entered into an arms race with one another, the winners of which were those groups that could create more complex forms of social organization based on $n$ e w cognitive abilities to interpret each other's behaviour. Chimps are unable to move to higher levels of social organization because they do not have language. The emergence of language among early human beings opened up huge new opportunities for both improved cooperation and cognitive development in an intimately linked fashion. Having language means that knowledge of who was honest and who deceitful no longer depends on direct experience but can be passed on to others as social knowledge. But language can also be the medium for lying and deceit. Any social group that evolved a slightly better cognitive capacity to use and interpret language, and therefore to detect lying, achieved advantages over its competitors. The development of language not only permits the short-term coordination of action but also opens up the possibility of abstraction and theory, critical cognitive faculties that are unique to human beings. Words can refer to concrete objects as well as to abstract classes of objects (dogs, trees) and to abstractions that refer to invisible forces (Zeus, gravity). Human beings are constantly observing correlations between events in the world around them and inferring causation from them. The ability to create mental models and to attribute causality to invisible abstractions is in turn the basis for the emergence of religion. From a cognitive point of view, any given religious belief can be described as a type of mental model of reality, in which causality is attributed to invisible forces that exist in a metaphysical realm beyond the phenomenal world of everyday 
that there are social rules they are expected to follow. They do not always do so, and the violation of group norms, or the defying of authority, is accompanied by what seem to be feelings of guilt or embarrassment."'(Fukuyama, 2011, pp.32-33) Political leadership ${ }^{16}$ in human groups emerges initially because members of a community admire a particular individual who demonstrates great physical prowess, courage, wisdom, or the ability to adjudicate disputes fairly. If politics is a struggle over leadership, it is also a story about followership and the willingness of the great mass of human beings to accord leaders higher status than themselves and subordinate themselves to them. In a cohesive and therefore successful community, this subordination is voluntary and based on belief in the

experience. (Fukuyama, 2011, pp.34-38). Similarly, Harari (2014) states "the truly unique feature of our language is not its ability to transmit information about men and lions. Rather, it's the ability to transmit information about things that do not exist at all. As far as we know, only Sapiens can talk about entire kinds of entities that they have never seen, touched or smelled. Legends, myths, gods and religions appeared for the first time with the Cognitive Revolution. This ability to speak about fictions is the most unique feature of Sapiens language. But fiction has enabled us not merely to imagine things, but to do so collectively. Myths give Sapiens the unprecedented ability to cooperate flexibly in large numbers. Sapiens can cooperate in extremely flexible ways with countless numbers of strangers." (Harari, 2014)

${ }^{16}$ There are three different leadership styles (i.e. a repeatedly shown pattern of leadership behaviour evident across a variety of situations): autocratic leadership (directive, non-participative, domineering behaviours); democratic leadership (participative, communicative, egalitarian); and laissez-faire leadership ('hands-off' leadership, with few attempts made to influence others at all). (Hewstone, Stroebe \& Jonas, ed., 2012) 
leader's right to rule. As political systems develop, recognition is transferred from individuals to institutionsthat is, to rules or patterns of behaviour that persist over time, like the British monarchy or the U.S. Constitution (Fukuyama, 2011, p.42). Therefore, who takes which role in a group is dependent on personality and individual abilities. There are other factors that determine who is more and who is less influential. Several inequalities within a group, such as inequalities in participation and influence, are highly correlated because they are all derived from performance expectations. That is, because of specific characteristics of group members, other group members form expectations about the usefulness of each group member's contributions. These expectations then serve as a self-fulfilling prophecy: the greater the expectations, the more likely a person is to speak up, offer suggestions and be evaluated positively by the others.

The theory assumes that performance expectations are influenced by so-called status characteristics. A distinction is drawn between diffuse status characteristics (not necessarily related to the group task), including, for example, gender, age and race, and specific status characteristics, such as skills and abilities (i.e. characteristics that are necessary for the group task and previous task success). These characteristics carry certain cultural expectations about competencies. Higher expectations are formed for people who are more experienced, have a higher status in society more generally, or have a relevant area of expertise. Obviously, these expectations may sometimes be false (e.g. a woman may in fact be more competent than a man), but they nevertheless affect people's status in the group and the amount of 
influence they have. The reason is that expectations need to be explicitly falsified before they lose their influence, and as long as they are not falsified, they continue to have their effect in a self-fulfilling way. (Hewstone, Stroebe \& Jonas, ed., 2012)

To conclude, social norms exist in every society and are inherently the result of social interaction. Their role is to adjust behaviour of group members in their mutual interactions so that behaviour becomes regular and predictable. This facilitates and rationalises cooperation and enables groups to survive and strive. Which social norms exist in a given society depends mainly on the leading ideology (religion, culture etc.) of that society, which is further the result of the common experience of a group, triggered by external factors such as environment and other groups. As they develop so social norms also vanish or change. Depending on circumstances individuals and groups develop new behaviour that is in contradiction with the existing behavioural pattern (norms). That is the reason why it is important to study the cognitive and biological roots for human behaviour to understand and predict which fundamental mechanisms are at work when new social norms are developed under given circumstances. It is of even more importance when knowing that social norms are the fundamentals for the development of Law. 


\section{2.,,The Leviathan“" as the Source of Law}

"The more corrupt the state, the more numerous the laws." - Tacitus

The Leviathan ${ }^{17}$, as Hobbes refers to the State, is until today the most successful form of organisation of human society. It is a society above society, ruling all other social groups under its control. Basically, the State is a construct of loyalty and interests, based on a repetitive cooperation and coordination between people (also called institutions), mostly with clear hierarchies and competences between them, with common goals, backed by physical force (usually the most powerful) and restricted to a certain territory.

${ }^{17}$ Is a sea monster referenced in the Hebrew Bible in the Book of Job, Psalms, and Isaiah. Thomas Hobbes used this term as a metaphor for the state. The Leviathan is described by Hobbes as an artificial person whose body is made up of all the bodies of its citizens, who are the literal members of the Leviathan's body. The head of the Leviathan is the sovereign. The Leviathan is constructed through contract by people in the state of nature in order to escape the horrors of this natural condition. The power of the Leviathan protects them from the abuses of one another. 
M.Muharemović Law: The Essence

\section{The Rise of the State}

As to the question of the roots of the State, Fukuyama (2011, pp.82-96) explains that "virtually all peoples on earth were originally organized into tribes. They owed primary obligation not to a state but to kinfolk, they settled disputes not through courts but through a system of retributive justice, and they buried their dead on property held collectively by groups of kin. Over the course of time, however, these tribal societies developed political institutions. First and foremost was the centralized source of authority that held an effective monopoly of military power over a defined piece of territory-what we call a state. Political philosophers, anthropologists, and archaeologists can only speculate as to how the first state or states arose. There are several categories of explanation, including social contract, irrigation, population pressure, war and violence, and circumscription. Tribal societies can provide some degree of security, but can provide only limited public goods because of their lack of centralized authority. So if the state arose by social contract, we would have to posit that at some point in history, a tribal group decided voluntarily to delegate dictatorial powers to one individual to rule over them. The delegation would not be temporary, as in the election of a tribal chief, but permanent, to the king and all his descendants. And it would have to be on the basis of consensus on the part of all of the tribal segments, each of which had the option of simply wandering off if it didn't like the deal. It seems highly unlikely that the first state arose out of an explicit social contract if the chief issue 
motivating it were simply economic, like the protection of property rights or the provision of public goods. Tribal societies are egalitarian and, within the context of close-knit kinship groups, very free. States, by contrast, are coercive, domineering, and hierarchical. We could imagine a free tribal society delegating authority to a single dictator only under the most extreme duress, such as the imminent danger of invasion and extermination by an outside invader, or to a religious figure if an epidemic appeared ready to wipe out the community. The transition from tribe to state involves huge losses in freedom and equality. It is hard to imagine societies giving all this up even for the potentially large gains of irrigation. " Therefore, the State has never been created by a "social contract"; it has always been born in conquest and exploitation (Rothbard, 2009, p.11). ${ }^{18}$ The

${ }^{18}$ The theory of social contract is a fiction that presumes that all state and social order is derived from a contract between its members. But the reason for a such fiction is to legitimate the state and to have the legitimate right to criticise the state. A such contract is of course not a historical, or empirical fact but, according to Kant, it is a rational construct with the goal to obey every legislature to make laws that could have been the result of a common will of all people. But such a consensus is not practically possible, or is only possible under huge time and cost efforts, in large societies. And even when attempted, it would lead to social paralysis because decisions would be made very slowly or tailored to the level of the most risk averse members of society (Rodi, 2014, p.62). But, even the derived concept of representative democracy based on the concept of the social contract is, empirically seen, problematic. As Rothbard noticed (2009) : "The government does not in any accurate sense "represent" the majority of the people. But, even if it did, even if 70 percent of the people decided to murder the remaining 30 percent, this would still be murder and would not be voluntary suicide on the part of the slaughtered minority. Suffice it to say here that an individual's true agent or "representative" is always subject to that individual's orders, can be dismissed at any time and 
stakes have to be much higher and can be much more readily explained by the threat to life itself posed by organized violence. We know that virtually all human societies have engaged in violence, particularly at the tribal level. Hierarchy and the state could have emerged when one tribal segment conquered another one and took control of its territory. The requirements of maintaining political control over the conquered tribe led the conquerors to establish centralized repressive institutions, which evolved into an administrative bureaucracy of a primitive state. This is why Oppenheimer (1926, p.15), concluded that "The State, completely in its genesis ... is a social institution, forced by a victorious group of men on a defeated group, with the sole purpose of regulating the dominion of the victorious group of men on a defeated group, and securing itself against revolt from within and attacks from abroad. Teleologically, this dominion had no other purpose than the economic exploitation of the vanquished by the victors."

Although warfare may be a universal and necessary condition for state formation, it is not a sufficient one. It is only when increases in productivity take place within a geographically circumscribed area like a river valley, or when other hostile tribes effectively circumscribe another tribe's territory, that it is possible to explain the emergence

cannot act contrary to the interests or wishes of his principal. Clearly, the "representative" in a democracy can never fulfil such agency functions, the only ones consonant with a libertarian society."( pp.9-11) In this sense, a free market, a vigorous civil society, the spontaneous "wisdom of crowds" are all important components of a working democracy, but none can ultimately replace the functions of a strong, hierarchical government (Fukuyama, 2011, p.13). 
of hierarchical states. In uncircumscribed, low-populationdensity situations, weaker tribes or individuals can simply run away. But in places like the Nile valley, bounded by deserts and the ocean, or in the mountain valleys of Peru, that were bounded by deserts, jungles, and high mountains, this option didn't exist. In this situation, only one explanation remains for state formation: that religious ideas were critical to early state formation, since they could effectively legitimate the transition to hierarchy and loss of freedom enjoyed by tribal societies. Religious authority and military prowess go hand in hand. Religious authority allows a particular tribal leader to solve the large-scale collective action problem of uniting a group of autonomous tribes. To a much larger degree than economic benefit, religious authority can explain why a free tribal people would be willing to make a permanent delegation of authority to a single individual and that individual's kin group. The leader can then use that authority to create a centralized military machine that can conquer recalcitrant tribes as well as ensure domestic peace and security, which then reinforces the leader's religious authority in a positivefeedback loop. Virtually every state has relied on religion to legitimate itself. (Fukuyama, 2011, pp.82-96) ${ }^{19}$

${ }^{19}$ One remarkable result of state formation has to be briefly explained.
Namely, societies under similar geographic and economic conditions
and subject to similar external influences nonetheless developed very
different types of states. A dynamic contest model of the potential
competition between state (controlled by a ruler or a group of elites)
and civil society (representing non-elite citizens), where both players
can invest to increase their power can explain these differences. The
model leads to different types of steady states depending on initial
conditions. One type of steady state, corresponding to a weak state,
emerges when civil society is strong relative to the state (e.g., having 


\section{The Mechanisms of the State}

As it becomes obvious from the previous said, bearing in mind that the State is the primary power in a society, the State has the "natural" ambition to regulate human behaviour within society. To do this, it has to declare to its subjects which behaviour is desirable through formal written acts. This is done by passing a constitution, laws and by-laws (all general and abstract prescriptions of behaviour) ${ }^{20}$ within an authorised state organ or other forum, following a strict procedure, and by issuing court and administrative decisions (which represent concrete and individualised prescriptions after applying the general and abstract rules) To execute those rules (to become social norms) the State has to act through its agents and organs (institutions) and to have some sort of support in the

developed social norms limiting political hierarchy). Another type of steady state, corresponding to a despotic state, originates from initial conditions where the state is powerful and civil society is weak. A third type of steady state, which we refer to as an inclusive state, is also possible when state and civil society are more evenly matched. In this case, both parties have greater incentives to invest to keep up with the other, and this leads to the most powerful and capable type of state, while incentivizing civil society to be equally powerful as well. (Acemoglu \& Robinson, 2017)

${ }^{20}$ Usually general and abstract legal acts, due to their intended general applicability in society, are passed by collective organs like assemblies, as an expression of a broader social consensus, although such legal acts can be issued also by individuals based on their broad social legitimacy (especially by-laws). 
population. Any government ${ }^{21}$ (not simply a "democratic" government) must have the support of the majority of its subjects. This support, it must be noted, need not be active enthusiasm; it may well be passive resignation as if to an inevitable law of nature. It is necessarily true that the class constituting the State-the full-time bureaucracy (and nobility) - purchase allies among important groups in the population. Therefore, the chief task of the rulers is always to secure the active or resigned acceptance of the majority of the citizens. The King alone cannot rule; he must have a sizable group of followers who enjoy the prerequisites of rule, for example, the members of the State apparatus, such as the full-time bureaucracy or the established nobility. But this still secures only a minority of eager supporters, and even the essential purchasing of support by subsidies and other grants of privilege still does not obtain the consent of the majority. For this essential acceptance, the majority must be persuaded by ideology that their government is good, wise and, at least, inevitable, and certainly better than other conceivable alternatives. (Rothbard, 2009, pp.18-20) One important part of a such state ideology is also the notion that the State is just and fair, maintaining so peace and cohesion in society. Peace is kept by the state's army and police, a standing force that could also defend the community against neighbouring tribes and states. Property rights are enforced not by kin but by courts and legal systems that had the power to settle disputes and

\footnotetext{
${ }^{21}$ Nevertheless, it should be noted that, according to Dataism (a new paradigm -mental mode in science that sees the entire human species as a single data-processing system) distributed data processing works better than centralised data processing. For example, dictatorships use centralised processing methods, whereas democracies prefer distributed processing (Harari, 2016).
} 
compensate wrongs. In time, moreover, social rules were formalized as written laws rather than customs or informal traditions. These formal rules were used to organize the way that power was distributed in the system, regardless of the individuals who exercised power at any given time. Institutions, in other words, replaced individual leaders. Those legal systems were eventually accorded supreme authority over society, an authority that was seen to be superior to that of rulers who temporarily happened to command the state's armed forces and bureaucracy. This came to be known as the rule of law. Finally, certain societies not only limited the power of their states ${ }^{22}$ by forcing rulers to comply with written law; they also held them accountable to parliaments, assemblies, and other bodies representing a broader proportion of the population. Modern democracy was born when rulers acceded to formal rules limiting their power and subordinating their sovereignty to the will of the larger population as expressed through elections (Fukuyama, 2011, p.15). This emergence of the rule of law is basically based on an imagined order. Thus, different societies adopt different kinds of imagined hierarchies. The imagined order is inter-subjective ${ }^{23}$.

${ }^{22}$ There is today a wide range of views on the appropriate scope of the State, ranging from those who believe it should provide only the most basic of public goods, to those who think it should actively shape the nature of society and engage in substantial redistribution. As noted, all modern liberal democracies engage in some degree of redistribution, but the extent of state intervention varies significantly from the social democracies of Scandinavia to the more classically liberal United States (Fukuyama, 2014).

23 In order to understand this, we need to understand the difference between 'objective, 'subjective', and 'inter-subjective'. 
M.Muharemović Law: The Essence

An objective phenomenon exists independently of human consciousness and human beliefs. Radioactivity, for example, is not a myth. Radioactive emissions occurred long before people discovered them, and they are dangerous even when people do not believe in them. That means, every human being will be affected by radioactive emissions if exposed to them. The objective world is the result of interactions between the environment (independent of human will) and the human sensory system.

The subjective is something that exists depending on the consciousness and beliefs of a single individual. It disappears or changes if that particular individual changes his or her beliefs.

$\mathrm{T}$ h e inter-subjective is something that exists within the communication network linking the subjective consciousness of many individuals. If a single individual changes his or her beliefs, or even dies, it is of little importance. However, if most individuals in the network die or change their beliefs, the intersubjective phenomenon will mutate or disappear. The dollar, human rights and the United States of America exist in the shared imagination of billions, and no single individual can threaten their existence.(Harari, 2014) 
M.Muharemović Law: The Essence

\section{Law as an Ideology}

"And the people who have the doing in charge, whether they be judges or sheriff $s$ or clerks or jailers or lawyers, are officials of the law. What these officials do about disputes is, to my mind, the law itself." -Llewellyn

In legal theory we can detect three different types of conceptions of Law. The first are instrumentalist conceptions, in which Law is a tool of government, just like other tools which are designed and used to implement government policies. Such conceptions correspond to the rule by law, instead of rule of law. Law is regarded as a neutral instrument to achieve certain goals. In this view the function of criminal law is to prevent and repress crime, by whichever means best suited to the objective. The only criterion is relative effectiveness and/or efficiency. Secondly, we have critical conceptions of law, in which law is a tool to protect citizens against the government. Government authority is considered as something that does not depend on the law, but needs to be checked by the law, which is thought to have an intrinsic value. In this view the function of criminal law is not to fight crime but to police the police. Thirdly, we have relational conceptions of law, 
in which law is seen from the perspective of a constitutional democracy. From this perspective an effective and legitimate law is always both instrumental and protective, both constitutive and regulative for government authority, creating competences while at the same time limiting them.

Seen as a social practice, Law can be understood as a succession of actions and interactions which social actors are engaged in by following rules and by projecting normative expectations on each other. (Claes, Devroe \& Keirsbilck, ed., 2009, p.13)

\section{The Forms of Law}

Having identified the basic functions of Law, we have to resolve what Law actually is, more specific, in which form it exists relating it to the material world. As said before, it is created by the State, mostly in the form of written ${ }^{24}$ texts

\footnotetext{
${ }^{24}$ The human brain has been adapted to store and process only particular types of information. In order to survive, ancient hunter-gatherers had to remember the shapes, qualities and behaviour patterns of thousands of plant and animal species. But when particularly complex societies began to appear in the wake of the Agricultural Revolution, a completely new type of information became vital - numbers. Foragers were never obliged to handle large amounts of mathematical data. No forager needed to remember, say, the number of fruit on each tree in the forest. So human brains did not adapt to storing and processing numbers. Yet in order to maintain a large kingdom, mathematical data was vital. It was never enough to legislate laws and tell stories about guardian gods. One also had to collect taxes. In order to tax hundreds of thousands of people, it was imperative to collect data about people's' incomes and possessions; data about payments made; data about arrears, debts and fines; data about discounts and exemptions. When the
} 
that prescribe rights (authorisation to demand an action from other subjects or even from the State itself) and duties (authorisation of the state to demand or forbid certain actions within its power sphere) for individuals and groups within a given society. But the Law as such is only a statement of the State what is expected from its subjects (in the sphere of "ought"). That does not mean that this statements are followed by the subjects in the reality. This depends only of the effectiveness of the execution mechanisms that are at the disposal of a State. One option, on which is every state basically build, is the use of force and coercion to implement its will. But, it is almost impossible to rule a society over a longer period by only

amount of people and property in a particular society crossed a critical threshold, it became necessary to store and process large amounts of mathematical data. Since the human brain could not do it, the system collapsed. The data-processing system invented by the Sumerians is called 'writing'. Writing is a method for storing information through material signs. One type of signs represented numbers. The other type of signs represented people, animals, merchandise, territories, dates and so forth. the first texts of history contain no philosophical insights, no poetry, legends, laws, or even royal triumphs. The earliest Sumerian writing was a partial rather than a full script. Full script is a system of material signs that can represent spoken language more or less completely. It can therefore express everything people can say, including poetry. Partial script, on the other hand, is a system of material signs that can represent only particular types of information, belonging to a limited field of activity. Latin script, ancient Egyptian hieroglyphics and Braille are full scripts. You can use them to write tax registers, love poems, history books, food recipes and business law. In contrast, the earliest Sumerian script, like modern mathematical symbols and musical notation, are partial scripts. (Harari, 2014) 
using force and coercion. This is the point where the idea ${ }^{25}$ of Rule of Law arises. It is the idea that every action of the State is based on predictive, clear and, in some form, prescribed rules. I emphasise here that the Law is, nevertheless that it is created by the State and directed formally to its subjects, in the end only a promise that the State will react in a certain manner to resolve social conflicts. We can take as an example the sphere of private law, where it is primary on the subjects to regulate their obligations through contracts ${ }^{26}$. But when a party to a contract breaches its contractual obligations, the other party will address this issue to the State (namely the courts) that will enforce the obligation as promised in its legislation. If the subjects do not trust the State to enforce its own legislation, then they will act according to their own social norms to resolve social issues. That means that the State is always in competition with other social groups to impose or "sell" its vision of social behaviour, to make legal norms the leading social norms in society. To achieve this goal it has to promote the superiority of its Law by emphasizing that it is more just and fairer than other social norms in place and that it offers rational solutions to all social problems.

${ }^{25}$ Ideas are extremely important to political order; it is the perceived legitimacy of the government that binds populations together and makes them willing to accept its authority (Fukuyama, 2011, p.10).

${ }^{26}$ Even a contract is the result of actual social power relations since it is a good instrument to conduct social interactions in a peaceful manner, based on the parties' consensus. Otherwise, if there is no power balance between parties, or a power balance that is established by a third party (like the State), the more powerful party would impose its will to the weaker one. 
In this process Law becomes the leading ideology ${ }^{27}$ of the modern State.

In this sense, Karl Olivecrona argues that law 'exists' in a factual sense only: words are printed on pieces of paper or internalized in people's minds, but their significance is that they form a link in the chain of causation which results in certain courses of behaviour. In simple terms, law is little more than a form of psychology-it is a symbolic expression for the fact that the human mind responds in certain ways to various forms of social pressure. Given our psychological make-up and educational conditioning, certain behaviour patterns result. Lawyers and officials read the laws enacted by the legislature and, by virtue of their conditioning, they are induced to act in particular ways: the judge decides $\mathrm{X}$, the policeman enforces $\mathrm{X}$. When a revolution takes place, the revolutionaries seize the legal machinery and exert, through propaganda, psychological pressures on the people. As a result of their conditioning, members of society simply carry on as before. He concedes (with Kelsen) that a monopoly of force is required in order for the psychological basis of law to be effective, but suggests that once the new regime is established, the coercive element may be pushed into the background and applied only in exceptional circumstances. In most cases the psychological conditioning suffices. (Wacks, 2012, p.157)

\footnotetext{
${ }^{27}$ With the term ideology we in general name a specific set of connected or co-dependent concepts, values, and symbols which on one hand critically reflect and interpret the past and existing societal situation (a descriptive perspective) and at the same time determine which values and objectives the society should be orientated towards in the future(a prescriptive perspective)(Cerar, 2011, p. 394 ).
} 
This is why Law, as a psychological phenomena has, to do with perception of its recipients what Law actually is. A recent comparative study of legal consciousness, based on data collected through focus groups in England, Poland, Bulgaria and Norway, illustrates that the majority of people in England, Poland and Bulgaria (but not in Norway) perceive law in terms other than written texts and legal regulation. Ordinary people define and experience law in many different ways, depending on a range of factors such as their social positioning (some people are more exposed to the law and its institutions than others), the legal culture to which they belong (i.e. the external legal culture which reflects the general attitude of groups of people to law and differs from society to society) and the legal tradition and history on which their legal system is based. (Banakar, 2015, p. 93) Even states in international relations have different perceptions what the actual international law is. So, States frequently change their views about the content of customary international law (Goldsmith \& Posner, 2005, p.25). ${ }^{28}$

${ }^{28}$ States obey customary law, or more precise exert behavioural regularity in a given situation where:

a.) a coincidence of interest exists among states, or the need of cooperation, or coordination exist, to behave in that particular way,

b.) a state or a coalition of states with convergent interests force other states to engage in actions that serve the interests of the first state or states.(Goldsmith \& Posner, 2005, pp.27-34) 
The Idea of Law

But the question arises why does this mechanism of psychological engineering exist, looking from a sociological and evolutionary perspective. This has to do something with cooperation. "Large numbers of strangers can cooperate successfully by believing in common myths. Any large-scale human cooperation - whether a modern state, a medieval church, an ancient city or an archaic tribe - is rooted in common myths that exist only in peoples collective imagination. Two lawyers who have never met can nevertheless combine efforts to defend a complete stranger because they both believe in the existence of laws, justice, human rights - and the mone ${ }^{29}$ paid out in fees. Modern business-people and lawyers are, in fact, powerful sorcerers. The principal difference between them and tribal shamans is that modern lawyers tell far stranger tales." (Harari,2014)

Much of history revolves around this question: how does one convince millions of people to believe particular stories about gods, or nations, or limited liability companies? Yet

\footnotetext{
${ }^{29}$ Money is thus an universal medium of exchange that enables people to convert almost everything into almost anything else. Cowry shells and dollars have value only in our common imagination. Their worth is not inherent in the chemical structure of the shells and paper, or their colour, or their shape. In other words, money isn't a material reality - it is a psychological construct. Money is accordingly a system of mutual trust, and not just any system of mutual trust. Initially, when the first versions of money were created, people didn't have this sort of trust, so it was necessary to define as 'money' things that had real intrinsic value (barley). Humans can eat it. The real breakthrough in monetary history occurred when people gained trust in money that lacked inherent value, but was easier to store and transport.(Harari, 2014)
} 
when it succeeds, it gives Sapiens immense power, because it enables millions of strangers to cooperate and work towards common goals. The ability to create an imagined reality out of words enabled large numbers of strangers to cooperate effectively. But it also did something more. Since largescale human cooperation is based on myths, the way people cooperate can be altered by changing the myths - by telling different stories. Under the right circumstances myths can change rapidly. In 1789 the French population switched almost overnight from believing in the myth of the divine right of kings to believing in the myth of the sovereignty of the people. Consequently, ever since the Cognitive Revolution Homo sapiens has been able to revise its behaviour rapidly in accordance with changing needs. This opened a fast lane of cultural evolution, bypassing the traffic jams of genetic evolution. The behaviour of other social animals is determined to a large extent by their genes. DNA is not an autocrat. Animal behaviour is also influenced by environmental factors and individual quirks. Nevertheless, in a given environment, animals of the same species will tend to behave in a similar way. Significant changes in social behaviour cannot occur, in general, without genetic mutations. As far as we can tell, changes in social patterns, the invention of new technologies and the settlement of alien habitats resulted from genetic mutations and environmental pressures more than from cultural initiatives. For similar reasons, archaic humans did not initiate any revolutions. This is why it took humans hundreds of thousands of years to make these steps. In contrast, ever since the Cognitive Revolution, Sapiens have been able to change their behaviour quickly, transmitting new behaviours to future generations without any need of genetic or environmental change. This does not mean that 
Homo sapiens and human culture became exempt from biological laws. We are still animals, and our physical, emotional and cognitive abilities are still shaped by our DNA. Biology sets the basic parameters for the behaviour and capacities of Homo sapiens. The whole of history takes place within the bounds of this biological arena. However, this arena is extraordinarily large, allowing Sapiens to play an astounding variety of games. Thanks to their ability to invent fiction, Sapiens create more and more complex games, which each generation develops and elaborates even further. (Harari, 2014)

\section{The Enforcer of Law}

Bearing in mind that Law is, basically, the core ideology of a State and that the State is also nothing more than a legal fiction (it is not a physical object), it is justified to ask who then creates this ideas how individuals should behave in a society. As stated before, in its essence the State is a network of institutions, filled and governed by humans. This institutions "produce" Law. But, some institutions as legislative bodies only prescribe laws (in an abstract and general way) but do not execute them in reality. On the other hand, courts do make law and execute it (render concrete and individualised decisions), making so Law effective in reality. "To declare what the law is or has been is the province of the judiciary; to prescribe what it shall be in the future belongs to the legislature" (Wickersham,1912, p.610).

Thus, rules are the starting point of deliberations and, as such, they neither dictate fully what action should be taken 'nor exhaust the range of actions that may be properly 
taken'. Where an activity is itself created by legal rules, as in the case, say, of administrative agencies, informal rules often emerge in order to interpret the legal rules, or even to modify or marginalised them'. This means that once social systems import ideas from their environment, they translate them into their own operational logic (Galligan in : Banakar, 2015, p. 84). It becomes clear that only those institutions of a State that apply Law are actually those who interpret and execute the written provisions of laws and other legal acts, or the existing customs and jurisprudence, and by doing so, create their own Law that becomes materialized in legal norms. This is so, because the meaning of legal (written) acts is not exhausted by their semantic scope ${ }^{30}$.

As with rules in other social practices, the meaning of legal rules is wholly dependent on their use. Like all other social rules, legal rules have an open texture: their meaning is not encapsulated in the words, but reveals itself in the way the rule is used, followed, interpreted, enforced, and so on . This is the result of the general nature of the language used and the unpredictability of the social reality in which legal

30 The textual embodiment creates a gap between the author and the meaning of his text, extending the scope of the text because it can no longer be entirely determined by the author's intentions. Written law can guide interactions beyond the local context, providing the possibility to establish jurisdiction for communities of people who may never meet in person. Secondly, this results in a situation in which the addressees of legal norms are not necessarily the same as the addressors, as was the case in a face-to-face community of peers. This leads to conflicts of interpretation since a text cannot interpret itself and the author cannot control the way readers use his text.(Cleas, Devroe \& Keirsbilck, ed., 2009) 
rules, principles, and precedents are applied. Rules are not self-applying, as Wittgenstein noted, and their application is therefore intrinsically mixed with the facts of the case or, in other words, its context. In order to understand legal rules as meaningful, normative standards, legal practitioners and law-abiding subjects must be able to grasp the point of these rules, which presupposes an implicit know-how in dealing with these rules. If the meaning of legal rules is dependent on their use, then it stands as an unfortunate consequence that uncertainty and doubt can always occur as to their use (and meaning) in unforeseen circumstances. As lawyers and citizens, we all have an intuitive sense of the meaning and point of criminal offences such as rape or assault and battery. But what happens when we are faced with a case in which a man is forced by another to penetrate him? Does it count as rape? In such (often controversial) cases legal practitioners and citizens may fail to revert to their common sense understanding of the legal norm. A last implication of the open texture of law comes down to the fact that legal rules and legal decisions can never fully determine their application. If their meaning lies in their use, then the effect of legal interventions and the way these legal norms are administered, are to a certain extent always unpredictable. (Claes, Devroe \& Keirsbilck, ed., 2009, p.14) Corollaries such as lex certa and lex stricta contribute to the realisation of the neutrality of the State, to the extent that they prevent public officials from bringing in their own value judgements with regard to the punishability of certain actions and omissions (Claes, Devroe \& Keirsbilck, ed., 2009, p.93).

Especially continental legal practitioners have been taught to understand their law as a hierarchical, linear system of 
clear-cut rules, the application of which in concrete circumstances is often seen in terms of simple syllogistic reasoning. In this regard, Howard (2011) noticed that "making rules as precise as possible has become almost a religious tenet. Legal rules should be self-executing and aim toward solutions that can be carried into effect without discretionary administration. Through detailed rules, regulation would be made certain." So, he noticed, further, that " the regulatory system has become an instruction manual. It tells us and bureaucrats exactly what to do and how to do it. Detailed rule after detailed rule addresses every eventuality, or at least every situation lawmakers and bureaucrats can think of. This paradox is explained by the absence of the one indispensable ingredient of any successful human endeavour: use of judgment. But, lawmakers, would not be able to anticipate every future contingency. Indeed, language itself is too imperfect. But words, even millions of them, are finite. The range of possible future circumstances is infinite. One slip-up, one unforeseen event, and all those logical words turn into dictates of illogic. Context is vital in law, as it is in life. Modern law, however, presses as hard as it can to cover every eventuality. "(Howard, 2011). In this sense, it would be misleading to grasp the complex relation between the legislator and the judge in terms of simple syllogistic reasoning, since judges increasingly spell out explicitly and even reaffirm a law-making competence (Claes, Devroe \& Keirsbilck, ed., 2009, p.17). This is because, on the one hand, the relevant rules and precedents do not offer sufficient guidance for a decision; while on the other hand, the decision reached cannot be sufficiently justified by the relevant rules and precedents. In the light of the relevant facts the law reveals certain 'gaps', as it were, which have 
to be filled by factors other than the accepted sources of law. The contextual gaps of the law are often filled by principles and policies, by values and practices, by idealistic and pragmatic notions (Claes, Devroe \& Keirsbilck, ed., 2009, p.26). This is the reason why Howard (2011) states that "The common law is not a legislative enactment but the synthesis of general standards derived from countless court decisions. We must drive our cars reasonably, for example, or else be accountable to those we injure. The common law is the opposite of ironclad rules that seek to predetermine results. Application of the common law always depends on the circumstances. The most important standard is what a reasonable person would have done. Every principle has exceptions. More than anything else, the common law glorifies the particular situation and invites common sense. The common law is the philosophy of pragmatism, because its truth is relative, not absolute."

German constitutional case-law has established since the early 1950s a tradition in relaxing legality and lex certa. The German Constitutional Court (Court) acknowledged the necessity of general terms in criminalization due to the complexities in and permanent change to contemporary life, and the constant need to respond appropriately to each case. The Court also denied the existence of the obligation to define precisely and perfectly predictably all the elements of a criminal offence. The requirement of lex certa is not violated if the interpretation by the judge is needed to clarify general clauses and uncertain terms. (Claes, Devroe \& Keirsbilck, ed., 2009, p.96). The Court attempted to respond to the deeper problem that the requirement of a precise definition of criminal offences sits ill with the unavoidable vagueness of legal terms. The European Court 
of Human Rights explicitly recognised the undeniable role of judges in the process of making criminal law. Legal principles and fundamental rights are often in conflict with each other and, accordingly, require to be balanced against each other. This complex interaction between legal principles and fundamental rights brings legal practitioners and citizens often to the limits of their legal system. For the exercise of balancing shows itself to be extremely difficult, resulting in a perception that no ultimate, reasonable measure exists such as to create an equilibrium in one fashion or another. In such circumstances the margin of discretion becomes an unavoidable burden.(Claes, Devroe \& Keirsbilck, ed., 2009, pp.21-22). Jerome Frank was against the idea that certainty could be achieved through legal rules. If it were so, he argued, why would anyone bother to litigate? Even where there is an applicable rule, one of two opposite conclusions is possible. the statute's validity turned, not on the certainty of the applicable rule, but on the personnel of the court. We want the law to be certain, he suggested, because of our deep need for security and safety which is endemic to children. In the same way as a child places his trust in the wisdom of his father, so we seek in the law and other institutions a similar comforting security (Wacks, 2012, p. 151). Because of that, Llewellyn suggests that the focus of study should be 'shifted to the area of contact, of interaction, between official regulatory behaviour and the behaviour of those affecting or affected by official regulatory behaviour' (Wacks, 2012, p. 152). For Pound, the task of lawyers and legislators is 'social engineering'. The law, by identifying and protecting certain 'interests', ensures social cohesion. The purpose of social engineering is to construct as efficient a society as possible, one which ensures the satisfaction of the maximum of 
interests with minimal friction and waste of resources (Wacks, 2012, p.164). By eliminating any room for judgment or discretion, law will be the same for everyone. Fairness, however, is a far more subtle concept than making all the words on the page apply to everyone. Uniformity in law is not uniformity in effect. Uniformity in the common law, consisting of broad principles like the "reasonable person" standard, generally permits adjustment for the circumstances. This type of uniform principle is almost synonymous with fairness. Uniform application of a detailed rule, on the other hand, will almost always favour one group over another. Universal requirements that leave no room for judgment are almost never fair, even when the sole point is to assure fairness. ${ }^{31}$ (Howard, 2011) Making

${ }^{31}$ In 1973, a prominent New York lawyer and former judge, Marvin Frankel, had the idea that criminal sentences suffered from too much variation. He certainly had a point: There were stories of different judges imposing sentences ranging from nothing to twenty years for the same crime. His idea developed momentum, and a "sentencing commission" was established. The commission ultimately created a 258-box matrix from which federal courts had to calculate all jail sentences. Judges are now permitted only minimal leeway.

All the components of the sentencing grid-whether it was first offense, whether a weapon was used, how many drugs were sold - are the best that our smartest legal minds could come up with. All the judges would have to do is calculate the points. At last, many believed, we had created a fair and uniform way of treating criminal defendants. It all sounded perfect. Most who use it-judges, lawyers, prosecutorsconsider it a disaster. The sentence for a drug conviction, for example, increases with the quantity of drugs involved, measured by weight. Some lower-level thug driving a delivery truck, who probably did not know how much he was delivering, gets a life sentence, while a pusher who sells heroin to a child gets two years. The jail time for selling the same amount of LSD varies by ten years, depending on the material it is sold in; a sugar cube is heavier than tissue paper. Policemen and 
Law is all about establishing a fair balance, in general or in a concrete cases, between competing interests (e.g. between two equal rights, or between the individual and the general interest) To achieve this (call it justice), there must be a reasonable relation between the objective which is sought to be achieved and the means used to that end, or the punishments imposed by administrative bodies or courts must be in proportion to the relevant misconduct (e.g. the punishment of an offender should fit the crime).

The origins of law, seen as a complex institutionalised practice, are surely attached to the rise of modern State power and the need for a complex bureaucratic apparatus, but that practice is also shaped by a strong concern for legal guarantees against arbitrary State power. In a legal tradition governed by the rule of law, complex institutional structures are needed in order to create and ensure a system of checks and balances between different powers, which would also allow citizens to call public officials to account for their actions and decisions. (Claes, Devroe \& Keirsbilck, ed., 2009, p.20)

prosecutors now huddle over the complex 258-box grid in their offices, figuring out how to make arrests so that they can maximize sentences and gain more leverage. 
M.Muharemović Law: The Essence

\section{Rethinking the Rule of Law}

The concept of The Rule of Law is omnipresent, especially in recent legislation, scholarly papers, political debates and media. But, do we really know what the reality of this concept is? Sure, in theory it is the rule of laws and not of men (in a broader sense it entails the equality before law, human rights protection and checks and balance), but are we sure about that? Before tackling this concrete question, which I will try to answer in a concise, plain and precise way, I have first to refer to the question: which world we live in?

The world we live in is the world we perceive. This is the shortest possible answer to this question. Our perception of this world is enabled (or constraint) by our sensory system Pinel \& Barnes, 2018). Our sensory system includes not only receptor cells which react on stimuli from the outside world but also includes the processing of this information, previously transformed by our sensors in readable information to our brain (something like a compiler in computers). And in our brains we create the final picture of the world. Is this picture the representation of the objective world (if something like this exists)? By far, as cognitive 
science claims, no (see in: Gefter, 2016). Our whole perception is trimmed to one ultimate goal - survival in an environment (the objective world?) that exists around as and interacts with us (mainly sending us information in form of radiation, light and other stimuli which is prepacked in a way our sensory system can process). Furthermore, our perception, obeying the principle of survival and bearing in mind the limited data processing capabilities of our brains, is guided by emotions (see in : Wolfangel, 2018) which function as a sort of a filter by setting criteria which data is relevant in a concrete situation, enabling us to react in a most efficient way (without complex and time consuming data analysis) ignoring all other irrelevant data (when a lion approaches, you simply run and do not care about other things, because you are guided by the emotion of fear). All said before means that we, humans, as a whole, have an intersubjective perception, which we falsely call a objective one (it is the result of the subjective perceptions of all humans which, by default, possess the same sensory system). Nevertheless, we humans are the most effective data processing units, from what we know and until now (think of artificial intelligence). In this anthropocentric worldview we describe the observed (perceived) facts and the interaction between them and call the observed results of such relationships, if they are always the same for a given relationship (if nature behaves the same), natural laws (i.e. if I push a stone down the hill, it will roll down, not upwards. This is the result of the Law of Gravity). But, natural laws do not explain why the phenomenon exists or what causes it. The explanation of a phenomenon is called 
a scientific theory. And this human ability to create theories is the result of the ability to think in a mode of detached perception (to seek explanation based on incomplete information by inferring). That means that humans not only perceive reality (through the sensory system described above) but also create a reality that is not based directly on any concrete input of the outer world. This ability is an evolutionary advantage because humans, based on previous experience (stored perceptions of the reality which are not reproduced as a whole picture but are rather resembled every time we try to remember) mentally explore various combinations to predict a result of a planned action. Such mental mode allows us to make predictive models and ideas for future events, or to explain not directly observed past occurrences. But, it is risky to assume a future outcome (even past occurrences) without having all the relevant and testable information. There is always, as Taleb (2018) remarks, a chance of hidden evidence or random events. Even the nature is only to some point (on the macro level) predictable, but as quantum physics shows (see in : Orzel, 2015) nature on the subatomic level is unpredictable (at least for our cognitive abilities), much like the human free will in the social sciences. It seems that humans, as an inevitable part of nature, are much like quants, or at least it appears to be so. Because of all the aforesaid, it is, as Hayek (1974) knew, naive to claim knowledge about future behaviour of humans (as most statistics in social sciences claim based on unrealistic models, even if we know that statistics is the average or aggregate, not applicable on every single observation, contrary to natural laws who hold 
on every single observation) since we have to acknowledge that the free will of one individual is almost unpredictable and unmeasurable (note that mathematics can not describe emotions), but on the scale of social interactions (which is the only relevant and natural situation to study for a social scientist) there is even a more complex structure of wills and actions. As Taleb noticed: "the main idea behind complex systems is that the ensemble behaves in ways not predicted by its components. The interactions matter more than the nature of the units." That is why the same author concludes: "The psychological experiments on individuals showing "biases" do not allow us to automatically understand aggregates or collective behaviour, nor do they enlighten us about the behaviour of groups".

\section{The Uncertain Dynamics of Society}

The point is that we exist in a uncertain, random, nonstatic (maybe some processes appear in the human eye static on the macro level, but on the micro level they are not), probabilistic, interconnected and, therefore, fragile environment that we try to cope with by creating unrealistic and static models of our world (even geometry is not a true representation of the perceived natural world, or have you ever seen a perfect circle or triangle created by nature? It is a geometrical idealisation). Law, as an attempt of formalization of social life by a " violence exercising" entity (mostly called a state which has the pretension to monopolise this violence) is an example of an idealised, theoretical and static model. When such model is 
proclaimed the basic principle on which a society has to function then it becomes an ideology, the ideology of the rule of law. Contrary to law, we have social norms that evolved "naturally" (for human beings) in numerous social interactions and they function, or when not, they disappear. As Taleb remarks "Wherever you look across societies and histories, you tend to find the same general moral laws prevailing, with some, but not significant, variations: do not steal (at least not from within the tribe), and similar interdicts. And we can see these rules evolved over time to become more universal, expanding to a broader set, to progressively include slaves, other tribes, other species (animals) etc. And one property of these laws: they are black-and-white, binary, discrete, and allow no shadow." Similarly, Hayek noticed ( see in: The Essential Hayek), that most social norms (using here the term law) "that govern human interactions were not invented and designed by some great 'Law Giver', but instead, laws emerged without centralized design. The laws against murder, for example, is not the product of human intention or design. There was never a tribe or society in which the intentional taking of the lives of peaceful members of that tribe or society was acceptable and became unacceptable only when and because some elders, a wise leader, or a popularly elected assembly pronounced such killing to be wrong. Such killing is, to use a phrase from Anglo-American law, malum in se-it is wrong in itself. People do not tolerate murder in their midst; in some form or fashion they take steps to prevent murder and to punish-usually very harshly_-those who commit it. Such steps are taken even 
when there is no formal government to lead such efforts. The same is true for theft, fraud, arson, and many other violent and aggressive acts initiated against the persons and property at least of the people regarded to be citizens of the group. Some of these laws might be rooted in humans' genetic make-up. (Parents naturally will go to enormous lengths to protect the lives of their children and to ensure that their children's killers are punished appropriately. Similar, if less intense, sentiments are naturally felt for other family members and friends.) Other laws might be based more on mere social and religious Conventions."

This principle of "survival of the fittest norms" does not apply, in most cases, to law, since it does not follow empirical and functional criteria (either because of ideological reasons or politicians are afraid of repealing it, under pressure from those benefiting from current law). Think here of legislation of modern states. You can find there reasonable universal rules (like basic criminal law, tort law, contract law) that have evolved either as social norms or by reasoning of courts in numerous concrete cases and that have been later formalised by legislation (they have been socially proofed), but most of the legislation (laws and by-laws) of modern states is based on ideology, is non functional and unnecessarily complex (think of excessive criminalisation of all possible behaviour, administrative law, human rights law, intellectual property law, tax law etc.) The Courts ${ }^{32}$ of a State are, although more flexible and

${ }^{32}$ Courts in the state apparatus, contrary to the prevailing opinion, do not have an all- decisive role in establishing the rule of law. They have 
more "natural" in creating law, significantly and inseparably under the influence and guidance of legislation which makes them, in the end, part of the ideology of the rule of law. Here one should also iterate that even the rise of common law is the result of initial conscious intervention of royal courts in order to establish a uniform law on behalf of the king. But later, dealing with social problems, courts came up with new solutions, which made common law an evolving spontaneous order, in the sense Hayek stated. To be clear here, even the initial idea how to regulate a behaviour in a concrete social group is not a product of the majority, as Taleb argues "outcomes are paradoxically more stable under the minority rule - the variance of the results is lower and the rule is more likely to emerge independently across separate populations." This makes perfect sense as one should remember for example how the great monotheistic religions emerged (a tiny, but motivated minority, even individuals, established their vision of order to the majority). What a social norm differentiates from most of law, is that the initial idea has become actual social behaviour through numerous interactions which further lead to adjusting, refining and sometimes, given the stage of social development, to refuting a social (customary)

a limited role in this regard, since they decide post factum, as the, mostly, last interpreter of law. Think of the criminal procedure where the most decisive things happen in the investigation under the control (in the most criminal justice systems) of the police and prosecutor. The following court procedure can only be of limited scope, constrained by the facts derived from the investigation phase. That means that the rule of law is only attributable to a certain degree to courts and it depends on a wider circle of institutions and even the society as whole. 
norm (note that the same process generates language). This social processes are inherent to social life and the end results are not controllable by a central authority. A social norm is in the end always a constraint to individual behaviour (not always based on a voluntarily basis) in order to make social life relatively predictable (with predictability comes trust, an essential part of functioning societies) and stable, thus possible. Social norms are sticky and durable which is the reason that it takes time or/and great efforts to change them.

\section{Trying to Regulate Life}

The State, too, tries to generate new social norms, only through the means of legislation, which leads to more rapidly and deeply constraints of the freedom of action (the most important asset humans can have, because with freedom of action comes creativity, happiness and progress). Rules consciously designed by government, as Hayek stated, are "legislation." We obey legislation, though, only because government will fine, imprison, or execute us if we do not obey. So people who favour a more involved state in almost every aspect of social life, because they are afraid of individual responsibility, do not realise that every time the state "proclaims" and "gives" a right to someone or a social group, it creates on the other side an obligation and burden for someone else or other social group. Sometimes the State manages to balance these competing interests, but mostly it miserably fails which creates dissatisfaction on both sides of the spectrum 
because the one in favour of regulation end up disappointed (the State can not deliver due to unrealistic and inexecutable promises and to catch up it creates even more bureaucracy that intrudes more and more in every aspect of life) and the other side will fight and sabotage the regulations perceived as unfair.

Furthermore, when someone thinks that the State (actually it is an agglomeration of individuals interacting in a mostly hierarchical network of self interests, exercising physical force) acts primary in the interest of the majority of people (the common good) he or she should take notice of the empirically proven minority rule, which Taleb describes as follows: "It suffices for an intransigent minority-with significant skin in the game to reach a minutely small level, say 3 or 4 percent of the total population, for the entire population to have to submit to their preferences." Rothbard (2009), in this sense, emphasized: "We must, therefore, emphasize that 'we' are not the government; the government is not 'us.' The government does not in any accurate sense 'represent' the majority of the people." That is why one should be aware that "popular power can be tainted with the same poison as personal power"(Wickersham, 1912,p.605).

Every minority group that wants to impose its view to the majority has (through norm creating) either to use physical force (a short time investment) or persuasive means like ideology (a long time investment). The State uses both strategies, resolving so the collective action problem. But, as Taylor (2017) noticed, "Any state, no matter how 
powerful, cannot rule solely through the use of brute force. There are too few rulers and too many of us for coercion alone to be an effective means of control." By creating an ideology, like the sense of belonging to a greater collective (nation) or the concept of the rule of law, not by men, the State acts on the psychological (emotional) level of humans which is the deepest possible level to reach for the purpose of controlling behaviour. The State (the ruling social group) creates so the perception of legitimacy.

Reality vs. Paper

When the State, based on its perceived legitimacy, legislates, someone (still humans, although one should consider the future AI development) has to apply the legislation. The first problem arises here, as Hasnas (1995) states, that "law consists of contradictory rules and principles, sound legal arguments will be available for all legal conclusions, and hence, the normative predispositions of the decisionmakers, rather than the law itself, determine the outcome of cases. For even if the law were consistent, the individual rules and principles are expressed in such vague and general language that the decisionmaker is able to interpret them as broadly or as narrowly as necessary to achieve any desired result." That is why Justice Oliver Wendell Holmes argued that certainty in law is an illusion; judicial decisions rely more on the language of logic than they do on objective enforcement. The second problem, which is connected with the first one, lies in the very same people who interpret and apply law. In this manner, Taylor 
stated that "Legislative edicts are always subject to the biases and agendas of those who interpret them, and will be imposed in this manner by whoever currently wields the power of the monopoly state over society." Because of that aforementioned, someone would ask how is it possible that the law is relatively stable and certain. This is the case, as Hasnas concludes, because "The stability of the law derives not from any feature of the law itself, but from the overwhelming uniformity of ideological background among those empowered to make legal decisions.... It should be clear that, culturally speaking, such a group will tend to be quite homogeneous, sharing a great many moral, spiritual, and political beliefs and values. Given this, it can hardly be surprising that there will be a high degree of agreement among judges as to how cases ought to be decided. But this agreement is due to the common set of normative presuppositions the judges share, not some immanent, objective meaning that exists within the rules of law." One should note here that individuals who serve the cause of a state when applying its law are not, and cannot be by the very nature and purpose of a state, primary focused to deliver substantial justice to the parties involved in a dispute, because by using the prescribed law they deliver formalised justice that has the purpose to create a balance in society (the general perception of a fair and just legal system that works). Of course, it is a philosophical question if substantial and individual tailored justice is even possible in a human society. This is the reason why law seems to "function" and we call it then "rule of law". 
Having in mind everything said above, we can conclude that our survival and success in our perceived world, given our sensory limitations, is only possible on experience based knowledge (try and error, paired with time that is the only criterion as Taleb notes) because what exists, functions, what failed, did not (the reader can apply this criterion to socialism). Therefore, knowledge has always to rest, as Karl Popper suggested, on testable (repeatable) empirical evidence (in order to enable falsification, not to proof the existence of actual knowledge!), having in mind the possible existence of hidden evidence and minimizing theories that are too far from reality. That is why excessive legislation based on ideological assumptions will always fail $^{33}$. One should be aware of the fact that social norms are one form of risk management and that should also be the purpose of law. Social norms do not arise without stimuli from the outer world or social pressure, contrary to law. That is why the great fallacy in social science, and therefore in law, is that we try to explain and predict human action by relying on what people (after being asked) say to feel or think and we build theories (laws) based on such biased data, ignoring actual and experienced behaviour. As Taylor concludes, "in order for a society to have peace and order, there needs to be a set of largely uniform and neutral laws in which the vast majority of the public agree are fair and just. Throughout the history of Western law, a decentralized

\footnotetext{
${ }^{33}$ In this regard, it is also a misconception that more laws mean more justice and more rule of law. As Wickersham (1912) noted :" it is far easier to draft constitutions and write laws than to find competent and honest men to administer them"(p.602)
} 
process of trial-and-error, competing courts, and private arbitration achieved these rules." This does not mean that, as it becomes more and more the case, courts of a state should be the universal dispute resolver ${ }^{34}$ in a society and thereby the only law creator (this is the process in which courts absorb the other branches of power, or simply judicialization) because this is, in the long term costly, slow and not feasible on a greater scale and alludes an even greater involvement of the state. It is also dangerous to impose one set of rules that evolved in one community to another community. This is why Taleb concludes: "Universal behaviour is great on paper, disastrous in practice... We are local and practical animals, sensitive to scale... We should focus on our immediate environment: we need simple practical rules." Such rules should play a role like prices do in a functioning market economy. They should, through numerous information exchanges (interactions), convey the needed information in the most efficient and sufficient way (what the expected behaviour is in a concrete situation). In this sense, F. A. Hayek gave the

\footnotetext{
${ }^{34}$ Courts, personalized by judges, have probably always existed (based on historical data) in human societies in the one or other form. Every society faces disputes between individuals or groups within or with other groups. In such situation the dispute can be solved by force (if this scenario brings more benefits) or by referring the dispute to a person or group of persons with authority accepted by the quarrelling parties or to an authority that has another legitimation (based on social power, social status etc.) such as the State. To resolute conflicts, in a way that is accepted in a concrete society, is the main purpose of judges. Judges can be part of the executive branch (like kings) or can belong to a separate branch (the judiciary). But it is clear that only an impartial and independent judge can in the best way fulfil its core role.
} 
only possible measure of how far a State with its law should interfere in a society with the words: "In a market economy only basic and abstract rules are enforced - chiefly, the laws of property, contract, and tort, along with criminal sanctions against the initiation of violence, theft, and fraud. And these rules are almost all negative, in that they do not tell individuals what to do but, rather, only what not to do. The result is that each individual has wide scope to formulate his or her own plans-and wide scope in choosing just how to pursue those plans - without having first to secure permission from some authority. "

This is why good government (as form and administration of government which tends to the happiness of the greatest number of the people) means that the laws shall adequately express the moral sense of the greatest part of the community, that they be executed by a just, courageous and impartial executive, and expounded and applied by wise and independent judges. (Wickersham,1912, pp.602-603) Good governance acts as a kind of multiplicator because individuals and groups will more likely accept voluntarily the rules stated and executed by the State and will become so agents of the rule of law.

If justice is not delivered in the aforementioned way by the government, social trust will decline (which results in more regulations since people do not trust each other in their daily interactions and the State has instead to formalize and enforce such interactions), individuals will stop to belief with their hearts and minds in the promise of rule of law and, in the end, government becomes obsolete. 


\section{M.Muharemović Law: The Essence}

"Rules preclude initiative. Regimentation precludes evolution. Letting accidents happen, mistakes be made, results in new ideas. Trial and error is the key to all progress. Orthodoxy, not practicality, is the foundation of process. Its demons are corruption and favouritism, but the creed of this orthodoxy is a perfect uniformity. The original idea of the regulatory state was eminently practical: Hire qualified people and let them do their best under general rules without attempting to fill up the minute details."

(Howard, 2011) 


\section{Law between States}

"Covenants, without the sword, are but words and of no strength to secure a man at all."

\section{— Thomas Hobbes, Leviathan}

As I have shown in the previous chapters, Law is an inevitable product of state activity in the pursuit of regulating social behaviour. But, what regulates behaviour of states in their interactions? Is that really International Law?

The system of International Law

First of all, an international legal system always existed back to the appearance of the first states in human history. Since there were several states competing which each other for territory and resources, exerting and safeguarding their sovereign authority over a piece of land, trying to pursue their own interest by expanding influence and trying to establish peace in accordance with this interest, the necessity for a certain set of rules of conduct between 
states, to achieve the aforementioned goals, was obvious. This was the moment when international law was born. "Even in a world of selfish states, there will be times when states have common interests that make cooperation valuable and easy to achieve." (Guzman, 2008, p.25)

Since the development of human rights law, commerce and means of communication, new actors emerged on the international stage. International organizations, multinational companies and the individual gained certain rights and duties under international law, they became participants in international law. Although there are many theories who suggest that the individual is the real subject of international law, because states are just the sum of individuals, states are still the primarily actors of international law simple of the fact that they possess the power base that is inevitable in inter-state relations. It is out of question that the state power is always concentrated in the hands of individuals or groups, but this "power concentration" is in international relations conceived as a state. All the others participants also fall within the supreme authority of a state, i.e. the national legal order or are the expression of the will of states. "Despite the increasing range of actors and participants in the international legal system, states remain by far the most important legal persons and despite the rise of globalisation and all that this entails, states retain their attraction as the primary focus for the social activity of humankind and thus for international law"(Shaw,2008, p.197). In this sense, Carl Schmitt also stated that "the national normative order is the basis and the precondition of any normative order among States. The former influences the latter and an international normative 
order cannot exist without an internal one". (Goldsmith, 2005,p.30) Therefore, we can refer to the system of international law as a primary inter-state law.

Having identified the primary subject of international law, the state, we can identify the primary source of norms in international law, again the states (although there are other sources like international organizations, companies etc., but all they depend on, in the end, the acceptance of states). It is well established to qualify customs, treaties, universal principles etc. as the sources of international law, but they are just the forms in which the international norms appear. The realisation of those prescribed norms wholly depends how states actually behave in their relations. For instance, states will only enter into agreements when doing so makes them (or, at least, their policymakers) better off. In other words, "states enter into treaties for the same basic reasons that individuals enter into contracts. Treaties allow them to resolve problems of cooperation, to commit to a particular course of conduct, and to gain assurances regarding what other states will do in the future" (Softić, 2012, p.5). On the other side, the primary source of norms in international relations are customs, because customs arise more organically out of the actions of states, that means they reflect actual behaviour of states. Many of the foundational principles of international law (such as territorial sovereignty, sovereign equality, and even, at bottom, pacta sunt servanda) are still governed by customary law. The formation of customary international law rules is quite ambiguous and in fact customary law is dictated by only some states (mainly the powerful ones). 
M.Muharemović Law: The Essence

\section{The Limits of International Law}

Comparing the international law system with a domestic legal system it become apparent that there is "no existence of a recognised body to legislate or create laws, a hierarchy of courts with compulsory jurisdiction to settle disputes over such laws and an accepted system of enforcing those laws. Without a legislature, judiciary and executive, it would seem that one cannot talk about a legal order. The system of international law lacks of some key features that are inherent to the domestic legal orders. The reason for that is that the international law system is based upon the consent of states, which is the result of the formal principle of "sovereign equality" of states. But the rule of "nonbinding of international norms without consent" and of "non coercion in treaties" is only partial and relative. It is quite obvious, from an empirical standpoint of view, that more powerful states (power is measured by the influence that states exerts on the behaviour of other states based on their military force, economic strength etc.) dictate the rules of international law to less powerful states in international relations. The major difference between the international law and the domestic law is that the latter has a supreme authority (or at least, more or less, consolidated and clear power structures) on its territory-a functioning state which is capable of enforcing its laws and resolving divergent interests by its authority. The international law does not possess one supreme authority but rather about 200 sovereign states who are keen to defend their sovereignty against other states and to pursue their own interest. This is also the key factual limit of international law. 
But, it is clear that such a sovereignty in international relations is a relative one. The states who are endowed with more power can impose their will to a certain number of less powerful states, but no state has every in history reached the critical point of power where it could claim to have supreme authority over all other states. In this hypothetical situation there would be only one state, because there would be only one sovereignty. At that point there would be no need for an international law because there would be only a hierarchical domestic legal order. Such a scenario is quite unlikely, so there is only the option that powerful states, pursuing their own interest, cooperate with each other and, where it is possible, impose their will to other weaker states in accordance with the statement of Guzman that "states do not concern themselves with the welfare of other states but instead seek to maximize their own gains or payoffs."'(p.17)

When we speak of a state's interests it should be noted that these interest are formed by individuals and groups who are in power in every concrete state and depending on internal power struggles these interests can change over time. Sometimes these interests are not rational from the standpoint of international relations, but serve the purpose to protect the inner power base.

Coming back to the issue of sources of international law, as Guzman stated, regarding the nature of a international treaty “...is not clear what such a treaty would achieve. They are likely to behave in the same way with or without a treaty because of their shared interest in avoiding a military conflict." Here lies also the explanation why customs, 
treaties etc. are just the form/manifestation/declaration in which one international norm appears, because norms are the result of factual situations and norms are only fact when they indeed regulate, i.e. when subjects to whom they are addressed behave in the manner a norm requires. Applying this to the international law, one can conclude that only the factual situation, based on the actual power relations between states, is the relevant source of international law, or is the international law itself.

Thus, if a custom or a treaty is not effective, i.e. the states do not behave according to this norms, then it is neither a norm or source. Even when states behave according to the provisions of a treaty or custom, this is not the result of the treaty or custom, as a pure declaration of a norm, but the result of a factual situation, i.e. it is practiced because it is imposed by power or it is in the interest of a country. Obviously, it is a matter of "practicing" rather than "prescribing." Having in mind that there is no supreme authority in international relations, there is not one international law but there are as many as there are factual situations. So the question of the constitutive elements of customs is resolved in favor of the objective element (practice requirement) and because of this de facto situation (which is the result of the will of powerful states) other "weaker" states have an opinion iuris that this factual situation is obligating them. Hereby a sufficient practice should be understood as a "sufficient possibility of enforcing this practice". Because of the lack of a supreme authority and so the lack of an effective enforcing mechanism that could enforce the norms of international law to all states, the international law limits its scope to a partial/selective implementation of treaties, customs etc." 
Countries cannot be arrested and simply put in jail. Nor does this law have a vertical structure involving an authority operating over the heads of the states... International law is not based on commands backed by sanctions but instead rests on voluntary compliance. As a matter of fact, municipal law, or domestic national law, from Afghanistan to Zimbabwe counts heavily on the cooperation of the various citizenries. If a national government had to force every citizen to obey every law, that government would need to hire mercenary police officers equal in number to that country's citizens. Although there are enough law-breakers in every country to justify a prison system, people usually obey the law because they believe it is in their enlightened self-interest to do so"(Henderson, 2010, p.5).

On the other side, it is obvious that states, according to their interests, mostly voluntarily behave according to treaties or customary law, because if they violate the rules, they face reputational sanctions. There is also the element of reciprocity at work and a powerful weapon it can be. States quite often do not pursue one particular course of action which might bring them short-term gains, because it could disrupt the mesh of reciprocal tolerance which could very well bring long-term disadvantages. For example, states everywhere protect the immunity of foreign diplomats for not to do so would place their own officials abroad at risk. "But the point must be made that a state, after weighing up all possible alternatives, might very well feel that the only method to protect its vital interests would involve a violation of international law and that responsibility would just have to be taken. Where survival is involved international law may take second place" (Shaw,p.8). 


\section{M.Muharemović Law: The Essence}

From the abovementioned inter-state relations arises the international law. 
M.Muharemović Law: The Essence

\section{An Order beyond Law?}

"To attempt to imprison the law of a time or of a people within the sections of a code is about as reasonable as to attempt to confine a stream within a pond. The water that is put in the pond is no longer a living stream but a stagnant pool."'-Eugen Ehrlich

So far, I have shown that Law is only an idea, which can, but have not to, due to earlier mentioned reasons, become an actual social norm. This conclusion is important because starting from this premise we can via argumentum $a$ contrario conclude also that there has to be some other normative order(s) within a society if legal rules are not followed. It is clear that every social interaction underlies certain norms of behaviour because social life, in the long term, would be impossible if individuals would in every situation and every time behave different. It is the natural product of social life. Basically speaking, if I cannot reasonable expect that the other member of my group will behave in a predictable way in a given situation, I can not trust him and cooperation is not possible, which would lead to the decline of my group. It is not of importance for social functioning how and who creates the norm, because a social norm is always the result of social power relations, but it is 
important that such a social norm exists at all. So, social norms are the glue of society.

\section{Obeying Law}

But, in which situation Law is not followed by its recipients? Before tackling this question, one should first know why Law is obeyed at all. Reasons to obey Law might be prudential or moral. Prudential reasons are those that arise from self-interest. One may, for instance, obey the law out of fear of punishment or habit. One might feel morally obliged to obey the law because the legal and political system is fundamentally fair and just, or because by the virtue of one's membership in a society there is a consent to an obligation to obey its laws. Yet few have a choice; we do not ask for or have the opportunity to accept or reject the purported benefits, or to express our consent to laws (Wacks, 2012, p.267).

On the other side, it is generally acknowledged that under certain circumstances it is morally acceptable to break the law or even that one might actually be under a duty to do so (Wacks, 2012, p.265). For example, the efficiency of law is endangered when the legal order prescribes a behaviour that is to widely and abruptly distanced from social norms. In this regard, if the law overlaps with social norms it is perceived as legitimate ${ }^{35}$. If there is to a certain degree a

\footnotetext{
${ }^{35}$ Legitimacy is the compatibility of the results of governmental output with the value patterns of the relevant systems, or less technical, a government is legitimate when it protects and enhances the values and
} 
discrepancy between law and social norms, there will occur, until some point, an adjustment of social norms to the law. But if the distance between law and social norm is to large, then the motivation to disobey the law grows, which leads further to the strengthening of the social norm that is opposed to the law. Such process could be observed during the prohibition legislation in the USA from 1920 to 1932 (Rodi, 2014, pp.145-146).

\section{Social Complexity as a Challenge to Law}

Another reason why some laws are not followed lies in the fact that they are too complex for an average person to be executed in practice. When laws cannot be complied with, individual officials, who supposedly have no discretion, have complete power. This is why modern law is a game of parsing and logical intrigue. Wherever detailed provisions bend and twist, the observant lawyer will find a place where he can go and violate the spirit of the rules, or get an advantage over others, and do so with complete impunity (Howard, 2011). Even when rules regulate some areas in a clear and simple way, reality and complexity of life outdates this solutions or makes them obsolete and inadequate. This is the case with the discrepancy between copyright laws, which through international treaties and conventions have become uniformly established in most countries, but actual social behaviour in cyberspace deviates radically from the rules of copyright (Banakar,

norms of its citizens, when it preserves and expands their culture, and when it behaves itself in foreign affairs (Stillman, 1974, p.48). 
2015, p. 53). Similar, although banking and finance are regulated domestically (e.g. the Banking Act in the UK and the Glass-Steagall Act in the US) and internationally (e.g. the Basel Accords), the story of the elite traders who manufactured these complex derivatives nevertheless suggests that there are social spaces within which the tribe of bankers may roam free, beyond the reach of the usual forms of regulation and undeterred by external monitoring (Banakar, 2015, p. 270) This is also the reason why for business people the law of contract is far less important than the actual operation of commercial practice (Wacks, 2012, p.166).

Bauman (2005, p. 1) describes contemporary society in terms of 'liquid modernity', which refers to a society where 'the conditions under which its members act change faster than it takes the ways of acting to consolidate into habits and routines'. Under these 'liquid' conditions, human agency becomes increasingly disembedded, i.e. independent of social structures and free from institutional and traditional ties which previously constrained social action at the level of social interaction. Systems such as polity and law become less capable of responding to sociocultural complexity and moral diversity in their environment through further functional differentiation. Social forces, which could be evoked by law and polity to reshape society and mould behavioural patterns under the first stage of modernity, either become less effective or redundant, as formal regulation fails to keep pace with continuously evolving social structures.(Banakar, 2015, p. 
272) One extraordinary result of a such situation is the example of the cyberspace code. The Internet is a free and lawless zone that erodes state sovereignty, ignores borders, abolishes privacy and poses perhaps the most formidable global security risk. Besides, by the time the cumbersome government bureaucracy makes up its mind about cyber regulation, the Internet has morphed ten times (Harari, 2016). Lessig concludes that in cyberspace code is law'. It seems that because code and law produce comparable normative impacts he conflates the two. There are good arguments to stress the similarities of computer code and law. They both regulate behaviour whenever they constrain human interaction, and they are both constitutive for human interaction to the extent that they make specific actions possible, which would not be possible otherwise. Some legal scholars seem to suggest that the difference between legal and technological impact is that legal norms provide a person with a choice to obey or disobey, while technological restrictions force a person to comply with a rule. This is simply not correct. Both law and technology generate constitutive and regulative types of normativity. A generic definition of normativity would be 'the way humans or non-humans constrain human and non-human interaction'. Interaction between non-humans can be normative if it constrains the actions of, for instance, machines that will eventually constrain the actions of a human person. In that case we are fooling ourselves with the illusion that legal normativity provides a type of freedom that technological normativity would annihilate. (Claes, Devroe \& Keirsbilck, ed., 2009, pp.455-456) 
Technology can enforce action in ways the Law cannot hope to achieve. Since the beginnings of modernity, Law has increased its dependence on the written word. Modern law as text, is, if anything, dependent on the bureaucratic State for its enactment and implementation. To follow a text takes time, one reads from beginning to end, taking into account both the semantic reference between text and world and the syntactic connections between different textual elements. The study of written law has thus become a longterm affair, depending on the accumulation of systematic knowledge derived from a proliferation of interconnected texts. We must conclude that the technology which has served law for the last 500 years - written text - will have to be complemented with new technologies in order to achieve the objective of the law: adequate anticipation of the grounds on which we are judged, included, or excluded. The fact that specific technologies may achieve compliance to an extent which cannot be reached by existing legal means would easily provide good reason to choose such technological means to implement the relevant legal norms. Law will have to be technologically embodied and interpreted in ways that safeguard both its effectiveness and its protection (Claes, Devroe \& Keirsbilck, ed., 2009, pp. 459-462).

It is evident that social norms evolve, and Law has to cope with the pace of such processes. But, the evolution of social norms, in general, is beneficial to society, because, as Fukuyama (2011, p.44) states "the conservatism of 
societies with regard to rules is then a source of political decay. Rules or institutions created in response to one set of environmental circumstances become dysfunctional under later conditions."

As I have shown, Law as an idea, is not self-executing. It needs interpretation and application by its recipients (humans). In this process the recipients who have the final authority to decide what Law is are in reality the lawmakers. By application of Law they materialise it, bring it to life, and make Law so a social norm that regulates behaviour. It is an illusion that Law can only be applied by its recipients like an algorithm in computers. Even if that would be possible, that would be a very rigid, dump and limited application, resulting in conflicting and nonexecutable outputs. It is true that technology will enable law to be applied more efficiently, but humans are those who will finally have to decide what the Law is. Machines still do not have the capabilities to act creatively and to solve new arising situations. Thus, the question arises why some people still think that an algorithm style application of Law, without human pragmatism, discretion, judgment and creativity, will deliver better results in our justice systems, since even the machine developers today try to copy the human way of thinking -calling it machine learning. 
M.Muharemović Law: The Essence

\section{SOURCES}

Abbott, D. (2013). The Reasonable Ineffectiveness of Mathematics. Proceedings of the IEEE, 101 (10), 21472153.doi: 10.1109/JPROC.2013.2274907.

Acemoglu, D. \& Robinson, J.A. (2017). The Emergence of Weak, Despotic and Inclusive States. Retrieved from: www.enber.org/papers

Banakar, R. (2015). Normativity in Legal Sociology: Methodological Reflections on Law and Regulation in Late Modernity. Heidelberg: Springer Verlag.

Bhattacherjee, A. (2012). Social Science Research: Principles, Methods and Practices. Second Edition. Tampa, Florida, USA.

Cashmore, A. R. (2010). The Lucretian swerve: The biological basis of human behavior and the criminal justice system. PNAS, 107 (10), 4499-4504.

Cerar, M. (2011). The Ideology of the Rule of Law. ARSP: Archiv für Rechts- und Sozialphilosophie / Archives for Philosophy of Law and Social Philosophy, 97 (3), 393-404. 
M.Muharemović Law: The Essence

Chynoweth,P.(2008). Legal Research. Retrieved from: http://www.csas.ed.ac.uk/_data/assets/pdf_file/0005/6654 2/Legal_Research_Chynoweth_-_Salford_Uni..pdf

Claes, E., Devroe, W. \& Keirsbilck, B. (Ed.) (2009). Facing the Limits of the Law. Heidelberg: Springer Verlag.

Drobak, J. N. (ed.) (2006). Norms and the law. Cambridge: Cambridge University Press.

Epstein, L.\& Martin, D.A. (2014). An Introduction to Empirical Legal Research. Oxford: Oxford University Press.

Fraser Institute. ( 2015). The Essential Hayek. Retrieved from : http://www.essentialhayek.org

Fukuyama, F. (2011). The Origins of Political Order: From Prehuman Times to the French Revolution. New York: Farrar, Straus and Giroux.

Fukuyama, F.(2014). Political Order and Political Decay: From the Industrial Revolution to the Globalization of Democracy. New York: Farrar, Straus and Giroux.

Gaerdenfors, P. (2006). How Homo Became Sapiens: On the Evolution of Thinking.

Oxford :

Oxford University Press.

Gefter, A. (2016). The Evolutionary Argument Against Reality. In: Quantamagazine. Retrieved from: https://www.quantamagazine.org/the-evolutionaryargument-against-reality-20160421/ 
M.Muharemović Law: The Essence

Goldsmith, J.L. \& Posner, E.A. (2005) The Limits of International Law. New York: Oxford University Press.

Guzman, A.T. (2008) How international law works: a rational choice theory, Oxford: Oxford University Press.

Harari, Y. N. (2014). Sapiens : A brief history of humankind. Signal Books.

Harari, Y.N. (2016). Homo deus: a brief history of tomorrow. Signal Books.

Hasnas, J. (1995). The Myth of The Rule of Law. Retrieved from:

http://faculty.msb.edu/hasnasj/GTWebSite/MythWeb.htm

Hayek, F.A. (1952). The Sensory Order. Chicago: The University of Chicago Press.

Hayek, F.A. (1974). The Pretence of Knowledge. Retrieved from: https://mises.org/library/pretense-knowledge

Henderson, C.W. (2010). Understanding International Law. Chichester: Willey-Blackwell.

Hewstone, M., Stroebe W. \& Jonas, K. (ed.). (2012). An Introduction to Social Psychology. West Sussex, UK: BPS Blackwell. 
M.Muharemović Law: The Essence

Hoffman, D. D. (2016). The Case Against Reality. In: The Atlantic.

Retrieved from: https://www.theatlantic.com/science/archive/2016/04/theillusion-of-reality/479559/

Howard, P.K. (2011). The death of common sense: how law is suffocating America.

New York:

Random House Trade Paperbacks.

Krebs, D.L. (2008). The Evolution of a Sense of Justice. In: Duntley and Todd (Ed.). Shackelford Evolutionary Forensic Psychology: Darwinian Foundations of Crime and Law. Oxford Scholarship Online. DOI: 10.1093/acprof:oso/9780195325188.001.0001

Leslie, C. (1990). Scientific Racism: Reflections on Peer Review, Science and Ideology. Social Science and Medicine, 31, 891-912.

Lukić, R. (1979). Uvod u pravo. Beograd: Naučna knjiga.

McIntyre, L. (2006). Dark Ages: The Case for a Science of Human Behavior. Cambridge, Massachusetts : The MIT Press.

Meyer, A. (2015). Adams Apfel und Evas Erbe: Wie die Gene unser Leben bestimmen und warum Frauen anders sind als Maenner. Muenchen : C. Bertelsmann.

Oppenheimer, F. (1926). The State. New York: Vanguard Press.

Orzel, C. (2015). Three Experiments That Show Quantum Physics Is Real. In: Forbes. Retrieved from: 
M.Muharemović Law: The Essence

https://www.forbes.com/sites/chadorzel/2015/07/20/threeexperiments-that-show-quantum-physics-isreal/\#3371bf5f1ae5

Pinel, J.P.J. \& Barnes, S. J. (2018). Biopsychology, 10th edition. Essex: Pearson Education Limited.

Rodi, M. (2014). Ökonomische Analyse des Öffentlichen Rechts. Berlin -Heidelberg: Springer-Verlag.

Rothbard, M.N. (2009). Anatomy of the State. Auburn, Alabama: Ludwig von Mises Institute.

Shaw, M.N. (2008) International Law. The Sixth Edition, Cambridge: Cambridge University Press.

Softić, S. (2012) Međunarodno pravo. Sarajevo: DES.

Stillman,P.G. (1974). The Concept of Legitimacy. Polity, $7(1), 32-56$.

Taleb, N.N.(2018). Skin in the Game. Penguin Random House.

Taylor, R. (2017). The Myth of the Rule of Law. Mises Wire. Retrieved from: https://mises.org/wire/myth-rule-law

Wacks, R. (2012). Understanding Jurisprudence: An Introduction to Legal Theory. Third edition. Oxford: Oxford University Press. 
M.Muharemović Law: The Essence

Wickersham, G.W. (1912). The Judicial

Function.University of Pen. Law Review, 60 (9), pp.601623.

Wilson, E. (1998). The Biological Basis of Morality. In: The Atlantic. Retrieved from: https://www.theatlantic.com/magazine/archive/1998/04/th e-biological-basis-of-morality/377087/

Wolfangel, E. (2018). Das richtige Gefuehl. In: Spektrum.de. Retrieved from: https://www.spektrum.de/news/emotionenperfektionieren-kuenstliche-intelligenz/1566366 